\title{
Evaluating the influence of laser wavelength and detection stage geometry on optical detection efficiency in a single-particle mass spectrometer
}

\author{
Nicholas Marsden ${ }^{1}$, Michael J. Flynn ${ }^{1}$, Jonathan W. Taylor ${ }^{1}$, James D. Allan ${ }^{1,2}$, and Hugh Coe ${ }^{1}$ \\ ${ }^{1}$ Centre for Atmospheric Science, School of Earth, Atmospheric and Environmental Sciences, \\ University of Manchester, Manchester, M13 9PL, UK \\ ${ }^{2}$ National Centre for Atmospheric Science, University of Manchester, Manchester, UK \\ Correspondence to: Hugh Coe (hugh.coe@manchester.ac.uk)
}

Received: 29 April 2016 - Published in Atmos. Meas. Tech. Discuss.: 12 May 2016

Revised: 3 November 2016 - Accepted: 4 November 2016 - Published: 15 December 2016

\begin{abstract}
Single-particle mass spectrometry (SPMS) is a useful tool for the online study of aerosols with the ability to measure size-resolved chemical composition with a temporal resolution relevant to atmospheric processes. In SPMS, optical particle detection is used for the effective temporal alignment of an ablation laser pulse with the presence of a particle in the ion source, and it gives the option of aerodynamic sizing by measuring the offset of particle arrival times between two detection stages. The efficiency of the optical detection stage has a strong influence on the overall instrument performance.
\end{abstract}

A custom detection laser system consisting of a highpowered fibre-coupled Nd:YAG solid-state laser with a collimated beam was implemented in the detection stage of a laser ablation aerosol particle time-of-flight (LAAP-TOF) singleparticle mass spectrometer without major modifications to instrument geometry. The use of a collimated laser beam permitted the construction of a numerical model that predicts the effects of detection laser wavelength, output power, beam focussing characteristics, light collection angle, particle size, and refractive index on the effective detection radius $(R)$ of the detection laser beam. We compare the model predictions with an ambient data set acquired during the Ice in Clouds Experiment - Dust (ICE-D) project.

The new laser system resulted in an order-of-magnitude improvement in instrument sensitivity to spherical particles in the size range $500-800 \mathrm{~nm}$ compared to a focussed $405 \mathrm{~nm}$ laser diode system. The model demonstrates that the limit of detection in terms of particle size is determined by the scat- tering cross section $\left(C_{\text {sca }}\right)$ as predicted by Mie theory. In addition, if light is collected over a narrow collection angle, oscillations in the magnitude of $C_{\text {sca }}$ with respect to particle diameter result in a variation in $\mathrm{R}$, resulting in large particlesize-dependent variation in detection efficiency across the particle transmission range. This detection bias is imposed on the aerodynamic size distributions measured by the instrument and accounts for some of the detection bias towards sea salt particles in the ambient data set.

\section{Introduction}

Ambient measurements of aerosol properties are required to further our understanding of the role of aerosol in climate (Boucher et al., 2013) and the detrimental effects on human health (Pope and Dockery, 2006). The dynamic nature of atmospheric processes make the online measurement of aerosol properties very challenging, and the choice of techniques depends on the specific aerosol property of interest and the temporal resolution required. In the field of atmospheric science, the importance of refractory aerosols in atmospheric processes (Formenti et al., 2011; Hudson et al., 2011) has increased the demand for online measurement of size-resolved composition at low number concentrations.

In single-particle mass spectrometry (SPMS), highpowered laser pulses are used to vaporise and ionise ambient aerosols that have been focussed into a narrow particle beam. The generated ions are usually analysed by time-of- 
flight mass spectrometry (TOF-MS), providing detailed composition information on a particle-by-particle basis. This approach allows for aerosol particle number concentrations to be evaluated by particle composition as well as the probing of internal mixing state that cannot be done by bulk analysis techniques (e.g. Pratt and Prather, 2010; Zelenyuk et al., 2010; Reitz et al., 2011). The type of material that can be analysed is determined by the power and wavelength of the pulsed laser system, whilst the temporal resolution is related to the probability that a particle will be coincident with the laser pulse in the ion source, a phenomenon often referred to as hit rate. In many systems, optical particle detection is incorporated into the instrument to provide an external trigger to the pulsed laser - temporally aligning the laser pulse with the presence of a particle in the ionisation region, resulting in an increased hit rate.

The incorporation of two optical detection stages into the instrument allows the determination of particle velocity by measuring the time taken for particles to travel the known distance between two detection stages. When used with an aerodynamic lens inlet, particle velocity is a function of the vacuum aerodynamic diameter, allowing for a particle size measurement to be made in addition to the single-particle composition measurement made by the TOF-MS. In some instruments, the optical detection stage has also been used to optically size particles (Murphy and Thomson, 1995) and to directly measure light-absorbing properties (Moffet and Prather, 2009) by calculating the scattering cross section from the intensity of detected light. These tandem measurements of single particles allow for the direct linking of composition with physical properties such as size, shape, and density (Murphy et al., 2004; Vaden et al., 2011). The design of the optical detection stage has a strong influence on the overall instrument performance and has been the focus of much research (Murphy, 2007). The features of SPMS instruments have previously been described by Sullivan and Prather (2005), Nash et al. (2006),Murphy (2007), and Hinz and Spengler (2007).

Optical particle detection techniques are well established for the size-resolved counting of particles in optical particle counters (OPCs) (McMurry, 2000), which are similar in many respects to the optical detection systems employed in SPMS. Particles are detected by collecting the scattered light generated from the interaction of a particle beam with a continuous-wave (cw) laser. When employed in SPMS, the scattering signals need only exceed a certain threshold to register a particle event, unlike standard OPCs, which optically size the particle based on the magnitude of the scattering signal. Incorporating an optical system into the geometry of a SPMS creates additional design challenges.

Advances in laser technology have influenced the design and development of the optical detection stage in SPMS. Early instruments utilised a helium-neon gas laser with a wavelength of $633 \mathrm{~nm}$ (Hinz and Kaufmann, 1996; Prather et al., 1994; Murphy and Thomson, 1995) with an output in the range of $4-10 \mathrm{~mW}$. The implementation of $532 \mathrm{~nm}$ $\mathrm{Nd}$ :YAG solid-state lasers with an output in the range of $50-300 \mathrm{~mW}$ greatly improved laser fluence and beam quality in later-generation instrument (Thomson et al., 2000; Su et al., 2004; Zelenyuk and Imre, 2005; Brands et al., 2011). Other groups have opted for newly developed laser diodes (Gaie-Levrel et al., 2012) that, while producing less output $(40 \mathrm{~mW})$, have shorter wavelengths $(405 \mathrm{~nm})$ and are relatively cheap and easy to implement. Shorter wavelengths are desirable when sampling particles whose diameter $(D)$ is smaller than the wavelength of the incident radiation as $C_{\text {sca }}$ is proportional to $D^{6}$ in the Rayleigh regime.

The most efficient particle detection systems use an elliptical mirror to collect scattered light over a wide angle, thus maximising scattering signal at the detector (Su et al., 2004; Zelenyuk and Imre, 2005). However, the physical dimensions of a standard elliptical mirror prevent the detection stage being located within the ionisation region. Consequently, it must be located upstream in the vacuum housing, and complex trigger circuits must be made that produce a particle-size-dependent trigger delay (Zelenyuk and Imre, 2005). Such systems have excellent particle detection efficiencies but have a hit rate that is limited by the probability of hitting a detected particle with the pulsed laser.

Composition measurements with SPMS are usually considered qualitative due to shot-to-shot variations in instrument function and a strong matrix effect that influences the ionisation process (Reilly et al., 2000; Zhou et al., 2006; Reinard and Johnston, 2008). These phenomena result in ion signals that are not proportional to the mass of the chemical species and a particle number counting bias with respect to particle type. Numerous studies have reported quantitative or semi-quantitative results by using relative sensitivity factors to account for matrix effects (Gross et al., 2000), accounting for transmission and hit rate bias (Kane and Johnston, 2000), and calculating scaling functions by referencing conventional particle counters (Allen et al., 2000). Quantification of particle number concentrations by these methods requires large assumptions to made about particle properties such as shape, density, and refractive index, making the application to ambient aerosol difficult. For instruments that utilise elliptical mirrors for particle detection, the optical particle detection efficiency is usually only considered a limiting factor when assessing the low particle size cut.

Despite these limitations, SPMS has proven very useful in measuring relative trends in particle number concentrations and chemical markers. A number of custom-built instrument are in operation for laboratory, field-based, and aircraft-based studies. In addition, the commercially available aerosol timeof-flight mass spectrometer (ATOFMS) (model 3800, TSI Inc.) is operated by several research groups worldwide. Recent examples of the application of this instrument include source apportionment and mixing-state studies in urban environments (Healy et al., 2012; Dall'Osto et al., 2014; Giorio et al., 2015), the study of the atmospheric ageing of min- 
eral dust during long-range transport (Sullivan et al., 2007; Dall'Osto et al., 2010; Fitzgerald et al., 2015), and the characterisation of particles of low number concentration in the Arctic (Sierau et al., 2014). The direct comparison of the response of single-particle instruments with different designs (Middlebrook et al., 2003; Hinz et al., 2006) highlights the need to consider the factors that affect particle counting statistics in SPMS.

The laser ablation aerosol particle time-of-flight (LAAPTOF) spectrometer is a type of single-particle mass spectrometer manufactured by AeroMegt $(\mathrm{GmbH})$ and is in an early stage of commercial development. The instrument features an aerodynamic lens inlet (model LPL-2.5, AeroMegt $\mathrm{GmbH}$ ), a bipolar TOF analyser (TOFWerks AG), a novel particle detection system based on $405 \mathrm{~nm}$ laser diode technology, and a compact light collection optics assembly consisting of fibre optic guides that collect scattered light over a narrow scattering angle and is located directly in the ionisation region.

We present an evaluation of the instrument performance with the original instrument manufacturer (OEM) detection stage design that identified the optical detection system as a limiting factor in instrument performance. The instrument performance is compared with a customised detection system in which the detection laser is replaced with a fibre-coupled $532 \mathrm{~nm} 1 \mathrm{~W}$ Nd:YAG solid-state laser system with a collimated laser beam. The influence of detection stage geometry is evaluated using the customised detection system as the laser intensity distribution within a collimated beam is relatively simple to model because, unlike a focused beam, there is no variation along the beam axis due to depth of field.

\section{Description of instrumentation}

The instrument design has previously been described by Gemayel et al. (2016). Here, we provide a brief overview of the instrument layout and describe the modifications made to the optical detection system. A schematic layout of the instrument is shown in Fig. 1. Aerosol enters the instrument via a $100 \mu \mathrm{m}$ critical orifice and passes through an aerodynamic lens before beam expansion into the first low-pressure region of the instrument. The particle beam passes through second and third differentially pumped stages separated by skimmers that remove the majority of the gas phase. Detection stage 1 is encountered in the third pumping stage when the particles pass through a cw laser beam arranged orthogonally to the axis of the particle beam. After passing a differentially pumped aperture into the TOF vacuum region, the particles encounter detection stage 2, which is located within the extraction optics of the TOF analyser. Detection stage 2 triggers an excimer laser $(\mathrm{ArF} \lambda=193 \mathrm{~nm}$, model EX5, GAM) to fire an intense pulse in a direction that is co-axial but counterpropagate with the particle beam. The cloud of ions generated by the interaction of the material with the high-energy

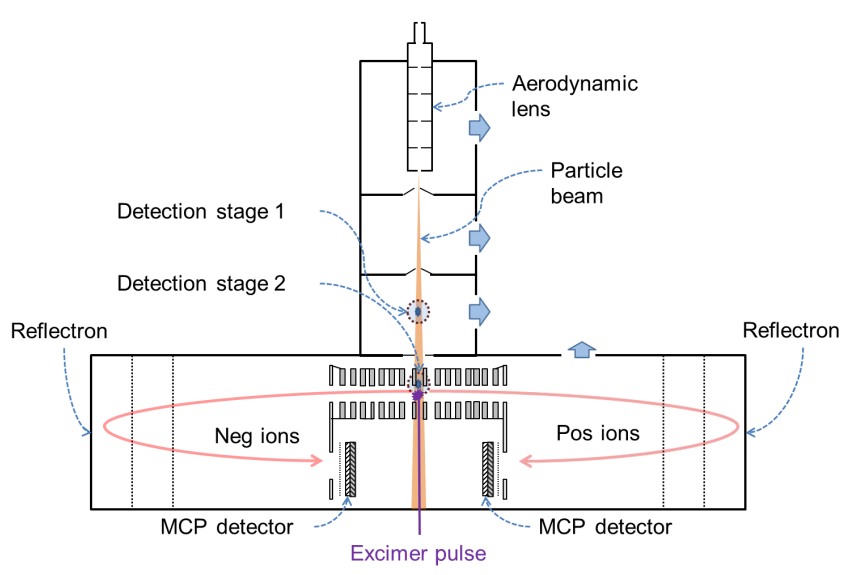

Figure 1. Schematic diagram of the LAAP-TOF instrument.

pulse is extracted into two linearly opposing TOF analysers, for positive and negative ions respectively.

Instrument control is performed using IgorDAQ software (AeroMegt Gmbh) based on IGOR (Wavemetrics), which incorporates TofDaq (TOFWerk AG) data acquisition. The instrument can be operated in three modes:

- Auto-trigger. The excimer is set to fire at a user-defined frequency (up to $100 \mathrm{~Hz}$ ), and mass spectra will be generated at a rate that is determined by the probability of a particle being synchronous with sufficient energy from the $8 \mathrm{~ns}$ excimer pulse in the ionisation region.

- Second laser only. The excimer laser will fire when it receives a trigger signal (with a set delay) from the detection stage 2 , increasing the probability of generating a mass spectrum.

- Both lasers. The instrument actively sizes particles, and a trigger is required from both detection stage 1 and 2 in order to fire the excimer laser.

The instrument features two optical particle detection stages which have very similar designs. A high-powered cw laser beam, arranged in a vertical orientation, passes through the instrument to a beam dump on the underside of the vacuum chamber. The instrument is aligned so that the particles in the particle beam interact with the detection laser radiation in a position where scattered light can be collected by a set of 12 optical fibres, arranged in a concentric pattern centred on the axis of the cw laser beam. The diameter of the circle is defined by the naked fibre termini, and the position below the axis of the particle beam is such that light is collected over an angle of $\sim 13-15^{\circ}$ with respect to the incident laser radiation at detection stage 1 and $\sim 10-12^{\circ}$ with respect to the incident laser radiation at detection stage 2 . The compact design of the collection optics allows the detection of particles within the ionisation region of the mass spectrometer which negates the requirement for size-dependent trigger delays that are a feature of some systems. 
(a)

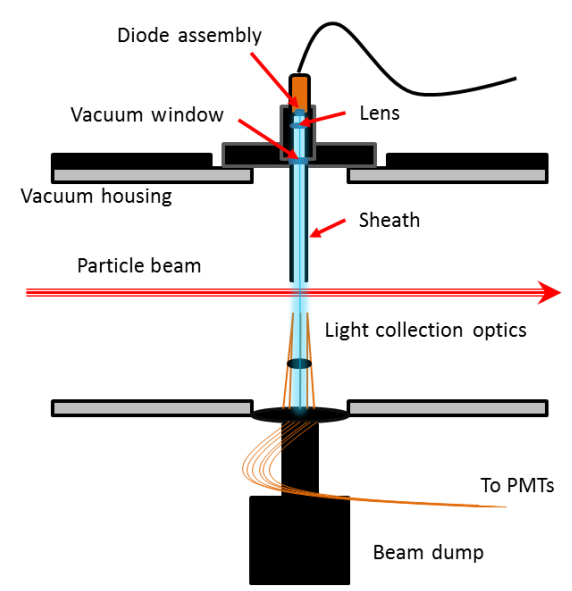

(b)

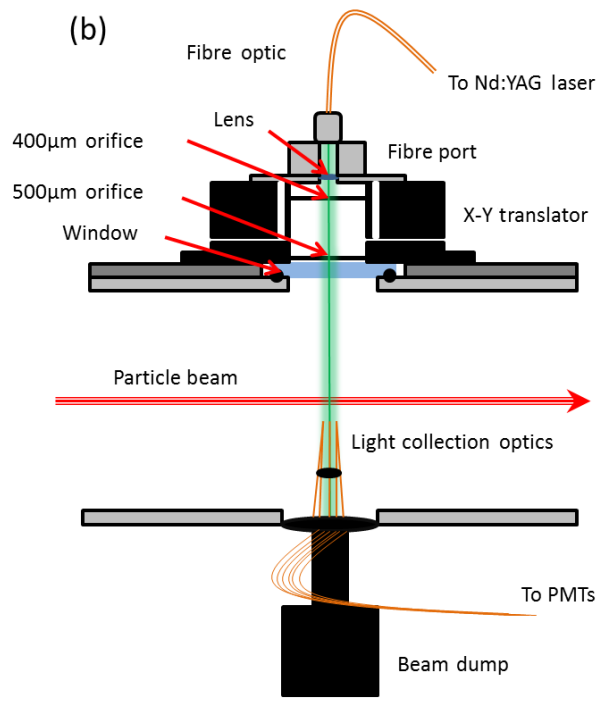

Figure 2. Schematic diagrams of the LAAP-TOF detection stages. (a) Detection system A featuring a $405 \mathrm{~nm}$ diode-based system with a focussed beam $(D 4 \sigma$ of $51.2 \mu \mathrm{m})$ and a sheath type spatial filter. (b) Detection system B featuring a custom-built $532 \mathrm{~nm}$ Nd:YAG DPSS fibre-coupled system producing a collimated beam with a $1 / e^{2}$ waist diameter of $330 \mu \mathrm{m}$, and spatial filtering outside the vacuum housing.

The optical fibres for light collection are connected to two photomultiplier tubes (PMTs) so that each PMT receives light from six fibres. A PMT signal pulse height above a userset threshold results in a transistor-transistor logic (TTL) pulse from the discriminator to the microprocessor control unit (MCU) in the timing electronics. A pulse is required from both PMTs in the detections stage in order for the MCU to recognise the presence of a particle. The thresholds are set experimentally by finding the minimum threshold value at which false triggers (noise) are not created - resulting in the discrimination between high-frequency noise and true particles, improving the signal to noise performance of the detection system in a similar set-up to that described by Trimborn et al. (2000).

In this study, two different systems of laser delivery are evaluated: detection system A, based on a laser diode emitting light at $405 \mathrm{~nm}$ that is focussed by a lens with a long focal length and spatially filtered with a sheath within the vacuum chamber, and detection system B, based on a custom-built fibre-coupled system featuring a Nd:YAG diode-pumped solid-state laser (DPSS), emitting at $532 \mathrm{~nm}$ that is collimated by a fiberport and spatially filtered by an orifice outside the vacuum chamber. Schematic diagrams of detection system A and detection system B are shown in Fig. 2a and $\mathrm{b}$ respectively. A summary of the key characteristics of the laser systems is given in Table 1.

Laser type is a fundamental choice that has an effect on the implementation, usability, and reliability of the system. Laser diodes have the advantage of being relatively cheap and easy to implement. However, diodes have a significantly shorter lifetime than a DPSS system especially if operated at or close to maximum output power. Consequently, the laser diode in
Table 1. Summary of the characteristics of the detection laser systems.

\begin{tabular}{lll}
\hline & System A & System B \\
\hline Laser type & Diode & DPSS \\
Wavelength & $405 \mathrm{~nm}$ & $532 \mathrm{~nm}$ \\
Max Power & $450 \mathrm{~mW}$ & $1 \mathrm{~W}$ \\
Typical operating output* & $50 \mathrm{~mW}$ & $300 \mathrm{~mW}$ \\
Beam type & Focussed & Collimated \\
Beam width & $51.2 \mu \mathrm{m}(D 4 \sigma)$ & $330 \mu \mathrm{m}\left(1 / e^{2}\right)$ \\
Spatial filter & Sheath & Orifice \\
\hline
\end{tabular}

* Typical operating power refers to the actual power delivered to the detection stage at typical operating setting and after beam focussing and filtering.

detection system $\mathrm{A}$ is operated at a fraction of the maximum available output power which is set by adjusting the drive to the diode. The output that is produced by a set drive voltage deteriorates over an diode-specific timescale, and, as the actual output can only be measuring with a laser power meter outside the instrument, there is some uncertainty as to the actual diode power output if the instrument is continually operated over a number of days or weeks.

In contrast, the Nd:YAG DPSS laser is specified as having an mean time to failure (MTTF) of $>400000 \mathrm{~h}$ at full power and automatically maintains output power to the userrequested value. However the system is much larger and more difficult to implement than the diode system, particularly in a transportable instrument. A fibre coupling was chosen to transfer the beam from the laser to the detection stage to eliminate the need for complex optomechanics. The coupling of a $3.3 \mu \mathrm{m}$ single-mode fibre in this set-up results in a 
power transmission efficiency of $40 \%$. The typical operation condition of this system produces an output of $300 \mathrm{~mW}$ in a collimated beam after spatial filtering.

Overall, the extra power available from the fibre-coupled system allowed for a larger detection beam width without significantly reducing the peak intensity produced by the tightly focussed diode beam. A more detailed description of the detection system designs can be found in Appendix B.

\section{Methods}

A number of methodologies were used to evaluate the instrument performance. The creation of aerosols in the laboratory was required for the instrument set-up procedure, instrument sensitivity testing, and the subsequent evaluation of performance of the particle detection system. Ambient sampling was carried out to measure the sensitivity of the instrument in atmospheric conditions and assess the suitability of the system for in situ measurement of size-resolved chemical composition of atmospheric aerosols.

\subsection{Laboratory experiments}

Monodisperse particles of polystyrene latex spheres (PSL) (Duke Scientific, Inc.) were produced using an atomiser aerosol generator (Topas GmbH, model ATM226) and a custom-built scanning mobility particle sizer (SMPS). The SMPS comprised a differential mobility analyser (DMA, TSI Inc., model 3081) and condensation particle counter (CPC, TSI Inc., model 3786-LP). The flow was divided between the CPC and LAAP-TOF after the DMA using an equal Y splitter and conductive tubing.

A measurement of the particle beam density profile was made using the detection laser to probe the particle density in a experiment similar to the optical detection method described by Petrucci et al. (2000). The optical detection stages were aligned onto the particle beam which was placed in a central position with respect to the instrument axis. The particle beam was then traversed in the horizontal axis (orthogonal to the detection beam axis) using the lens adjuster to pivot the inlet in the gimbal in $0.05 \mathrm{~mm}$ intervals. The number of particle pulses was measured over a $1 \mathrm{~min}$ period at each position using an oscilloscope. The lateral movement of the particle beam in the plane of detection can be easily calculated with simple trigonometry. A particle density profile was then constructed using the data.

\subsection{Field deployment}

The instrument was deployed for ground-based ambient aerosol characterisation during the Ice in Clouds Experiment - Dust (ICE-D) project in August 2015. ICE-D was a multiplatform field campaign with the primary aims of studying aerosol-cloud interactions during the evolution of towering cumulus clouds over the sub-tropical Atlantic Ocean. The project had significant aircraft and ground operations that involved the in situ characterisation of the properties of mineral dust advected from the Sahara region.

Ground-based aerosol characterisation took place at Praia International Airport, Santiago Island, Cabo Verde, from 27 July to 23 August 2015. The ground site comprised the Manchester aerosol container with a $30 \mathrm{~m}$ scaffold tower for ambient aerosol sampling. The tower supported a pumped inlet that was divided into heated lines inside the aerosol container, delivering ambient aerosol to a host of instruments, including the LAAP-TOF and an aerodynamic particle sizer (APS) (3321, TSI Inc.). The APS measures aerodynamic particle diameters in the range $0.5-20 \mu \mathrm{m}$ at a smpale flow rate of $1 \mathrm{~L} \mathrm{~min}{ }^{-1}$.

Previous studies at this location have recorded a multimodal aerosol size distribution with number concentrations in the size range $0.5-2.5 \mu \mathrm{m}$ of between 2 and $100 \mathrm{~cm}^{-3}$ for clean maritime conditions and dust events respectively (Kandler et al., 2011). With an inlet flow rate of $0.078 \mathrm{~L} \mathrm{~min}^{-1}$, the LAAP-TOF was required to accumulate mass spectra for $1-10 \%$ of particles present during the ICE-D campaign in order to measure size-resolved composition at a temporal resolution of several particles per minute.

\subsection{Instrument performance definitions}

To characterise the instrument performance, we describe the elements that contribute to the efficiency of the instrument in each acquisition mode. An aerodynamic lens focusses particles of different size and shape with different efficiency (Liu et al., 1995; Zhang et al., 2004). The transmission efficiency of the aerodynamic lens $\left(E_{\text {Lens }}^{d}\right)$ is defined as the proportion of spherical particles with physical diameter $d$ that exit the expansion nozzle relative to the number of particles that passed the critical orifice, i.e. a measure of the losses that occur within the lens assembly and critical orifice holder.

On supersonic expansion into the low vacuum of the instrument, a particle beam is formed whose solid angle of divergence relative to the lens axis defines a cross-sectional area at a set distance from the nozzle expansion. This area has a 2-D Gaussian probability density function (2DG-PDF) (Huffman et al., 2005). The probability of hitting a particle and obtaining a mass spectrum within this 2DG-PDF is defined as the hit rate efficiency $\left(E_{\mathrm{Hit}}^{d}\right)$ and is the product of the geometrical overlap of the excimer laser focal point with the particle beam $\left(E_{\mathrm{Geom}}^{d}\right)$, the temporal overlap of the peak UV laser power with the presence of a particle in ionisation the region $\left(E_{\mathrm{Temp}}^{d}\right)$, and the ionisation efficiency of the UV laser $\left(E_{\mathrm{Ion}}^{d}\right)$ with respect to the particle composition (Erdmann et al., 2005).

The overall efficiency of the instrument to generate a mass spectrum from an ambient aerosol population is acquisition mode specific. In the case of "auto-trigger" mode, the probability that a mass spectrum will be generated ( $\left.E_{\text {AutoMS }}^{d}\right)$ is simply the product of $E_{\mathrm{Lens}}^{d}$ and $E_{\mathrm{Hit}}^{d}$. The probability of hit- 

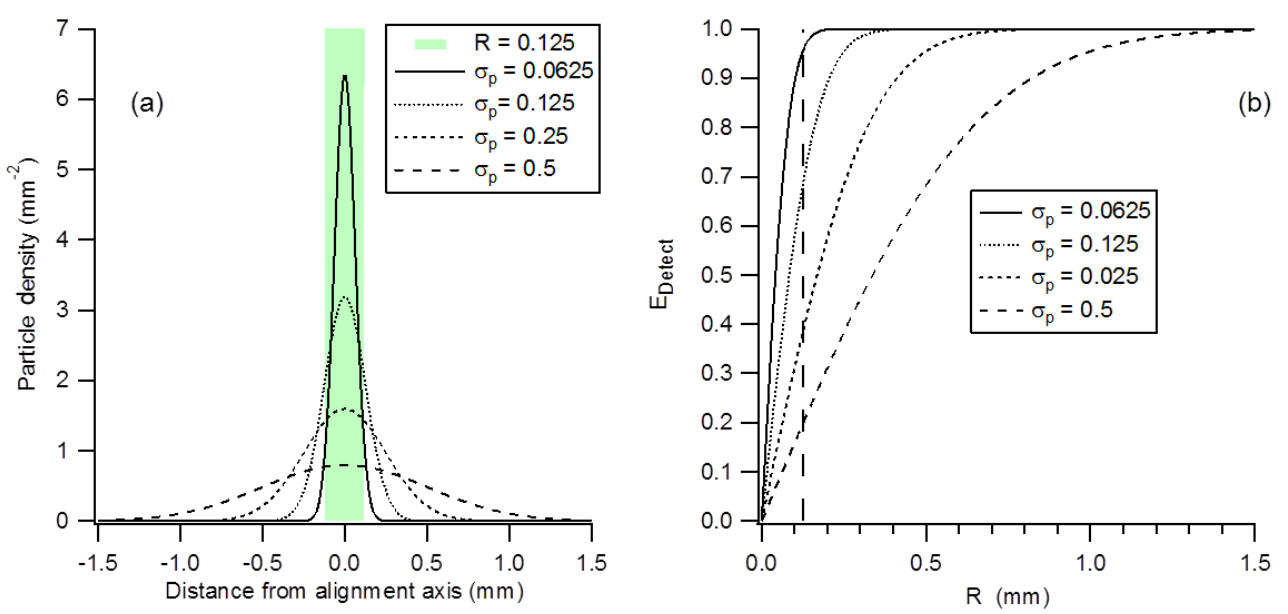

Figure 3. (a) The overlap of detection beam with a theoretical effective detection radius $(R)$ of 0.125 mm, with four normalised particle beams with widths $\sigma_{\mathrm{p}}=0.0625,0.125,0.25$, and 0.5 . (b) The relationship of the effective detection radius $(R)$ and detection efficiency ( $E_{\text {Detect }}$ ) for a range of $\sigma_{\mathrm{p}}$ values. $R=0.125 \mathrm{~mm}$ is marked for reference.

ting a particle and obtaining a mass spectrum in "secondlaser-only" mode includes an extra term relating to the sizedependent optical detection efficiency ( $E_{\text {Detect }}^{d}$ ). The hit rate is also modified with respect to free-firing mode because the term $E_{\text {Temp }}^{d}$ is modified to a probability relating to the trigger delay and the size-dependent particle velocity. In addition, the active area of the UV ionisation is assumed to be larger than the active area of detection, so that $E_{\text {Geom }}^{d}=1$ in this acquisition mode, providing the instrument is correctly aligned. We defined the overall efficiency of second-laser-only mode as $E_{\text {TriggeredMS }}^{d}$, and using the definitions above it is defined by Eq. (1). Note that all terms have a particle size dependence.

$E_{\text {TriggeredMS }}^{d}=E_{\text {Lens }}^{d} \cdot E_{\text {Detect }}^{d} \cdot E_{\text {Hit }}^{d}$

The third acquisition mode, referred to as "both lasers" in the software, involves the particle detection at both detection stage 1 and detection stage 2 so that the aerodynamic size of a particle can be measurement before the particle is ablated. The two detection stages will have different detection efficiencies because of slightly different geometries and different particle beam widths related to the down-stream distance from the nozzle of the aerodynamic lens. We defined the sampling efficiency in both-lasers mode as $E_{\text {SizedMS }}$.

\subsection{Model of the optical detection geometry with a collimated detection beam}

The portion of the divergent particle beam sampled by the orthogonally incident detection laser defines an active area of detection, where the intensity of the radiation exceeds a minimum threshold $\left(I_{\min }\right)$ to produce enough scattered light from the interaction of radiation with the particle for the detection system to register a particle event. The resulting efficiency of optical detection $E_{\text {Detect }}$ is a function of the active area of detection and the particle number density of the portion of the 2DG-PDF particle beam that it covers, which have a size and shape dependence. For simplicity, we modelled spherical particles, so the size dependence only was considered.

It has been shown that a 1-D Gaussian model is sufficient to quantify the amount of a particle beam blocked by a thin wire (Jayne et al., 2000; Huffman et al., 2005). In the case of optical particle detection by a collimated detection laser, we assumed that the detection beam is perfectly centred on the particle beam, so that the portion of the particle beam that was actively detected is the portion covered by an effective detection radius $(R)$ in the radial direction $(r)$ from the centre of the particle beam. The general relationship between particle beam width $\left(\sigma_{\mathrm{p}}\right)$ and $R$ in Eq. (2) was used to quantify $E_{\text {Detect }}$ for a certain particle diameter $d$.

$E_{\text {Detect }}^{d}=\frac{2}{\sqrt{\pi}} \int_{0}^{R} e^{R^{2} / 2 \sigma_{\mathrm{p}}^{2} \mathrm{~d} r}=\operatorname{erf}\left(\frac{R}{\sqrt{2} \sigma_{\mathrm{p}}}\right)$

The relationship between $R$ and $E_{\text {Detect }}$ is demonstrated in Fig. 3 for several particle beam widths. An $E_{\text {Detect }}$ of close to 1 is achieved when $R$ is equivalent to $3 \sigma_{\mathrm{p}}$ width. Note that, when $R<\sigma_{\mathrm{p}}$, doubling the $\sigma_{\mathrm{p}}$ has the effect of halving the detection efficiency. This loss of detection efficiency with $\sigma_{\mathrm{p}}$ diminishes when $R>\sigma_{\mathrm{p}}$.

The laser beam power density profile is also described by a 2DG-PDF orthogonal to the laser beam axis. As the particle beam is orthogonal to the laser beam axis, a 1-D Gaussian PDF describes the laser beam intensity profile that is encountered by particles as they cross the detection stage. The effective detection radius $(R)$ was modelled for a specific detection laser beam width $\left(\sigma_{\mathrm{d}}\right)$ by the relationship in Eq. (3). 

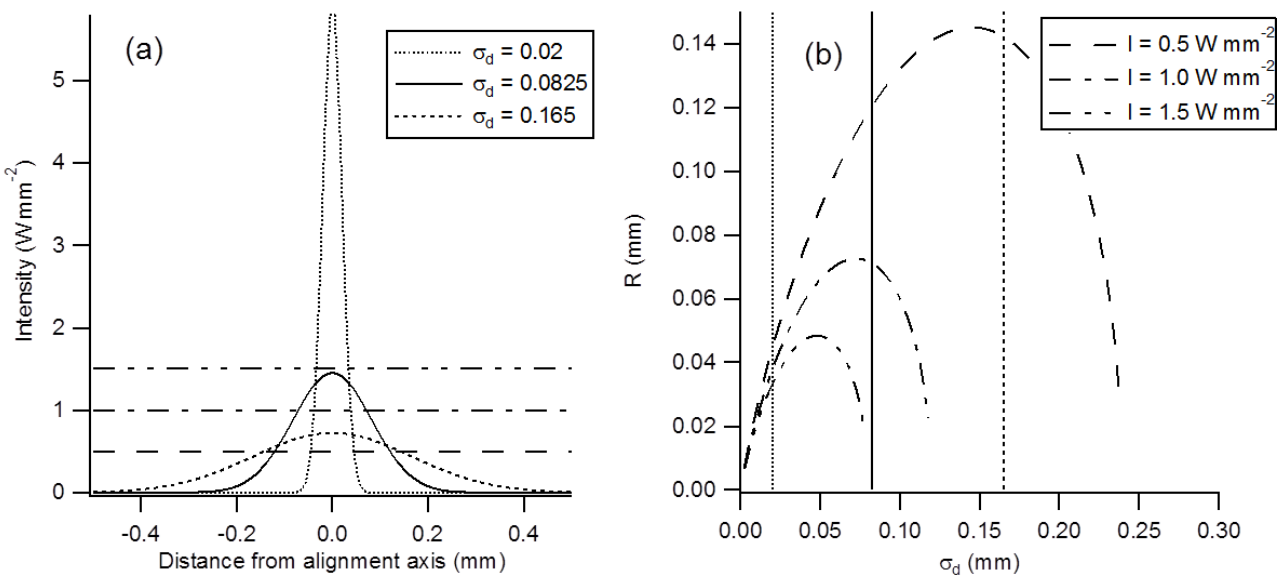

Figure 4. (a) Gaussian intensity distribution for collimated laser beams of fixed power focussed to detection beam width $\left(\sigma_{\mathrm{d}}\right)$ of $0.02,0.0825$, and 0.165 . (b) The relationship of the effective detection radius $(R)$ with respect to detection beam width $\left(\sigma_{\text {detect }}\right)$ for $I_{\text {min }}$ of $0.5,1.0$, and $1.5 \mathrm{~W} \mathrm{~mm}^{-2}$. The beam widths shown in the left panel are marked for reference.

$R=\sigma_{\mathrm{d}} \sqrt{-\ln \left(\frac{I_{\min }}{\sigma_{\mathrm{d}} \sqrt{2 \pi}}\right) \cdot 2}$

The effects of the relationship shown in Eq. (3) are two-fold. Firstly, the choice of detection beam width determines the active area of detection at a set $I_{\min }$. Secondly, $I_{\min }$ has a controlling influence on the portion of the collimated beam that will be active. Figure 4 demonstrates the relationship of $R$ and $\sigma_{\mathrm{d}}$ for set values of $I_{\min }$. In these examples, the output power of the laser is constant but collimated to a range of $\sigma_{\mathrm{d}}$ beam widths. For small detection beam widths, there is a weak dependence on $I_{\min }$ as most of the density profile exceeds the threshold (Fig. 4a). However, for larger detection beam widths, larger values of $R$ are produced at the expense of greater $I_{\min }$-dependent variability (Fig. 4b). For example, with a detection beam width of $\sigma_{\mathrm{d}}=0.0825 \mathrm{~mm}$, the effective detection radius $(R)$ at an intensity threshold of $0.5 \mathrm{~W} \mathrm{~mm}^{-2}$ is almost double that of an intensity threshold of $1.0 \mathrm{~W} \mathrm{~mm}^{-2}$ but will fail to detect particles with an $I_{\min }>1.25 \mathrm{~W} \mathrm{~mm}^{-2}$ as $R=0 \mathrm{~mm}$.

The magnitude of $I_{\min }$ is a function of the scattering cross section of the particle $C_{\mathrm{Sca}}$ and a transfer function $K$ that describes the minimum amount of power transfer to the detector required, and it accounts for the collection and transfer of light by the fibre optics, the radiant sensitivity of the detector, and the characteristics of the electronics in the trigger unit. The relationship between $I_{\min }, K$, and $C_{\mathrm{Sca}}$ is shown in Eq. (4). The transfer function is assumed to be the same for all particles (Jonsson et al., 1995), while $C_{\text {Sca }}$ has a strong dependence on the size and refractive index of the material.

$I_{\min }=\frac{K}{C_{\text {Sca }}}$

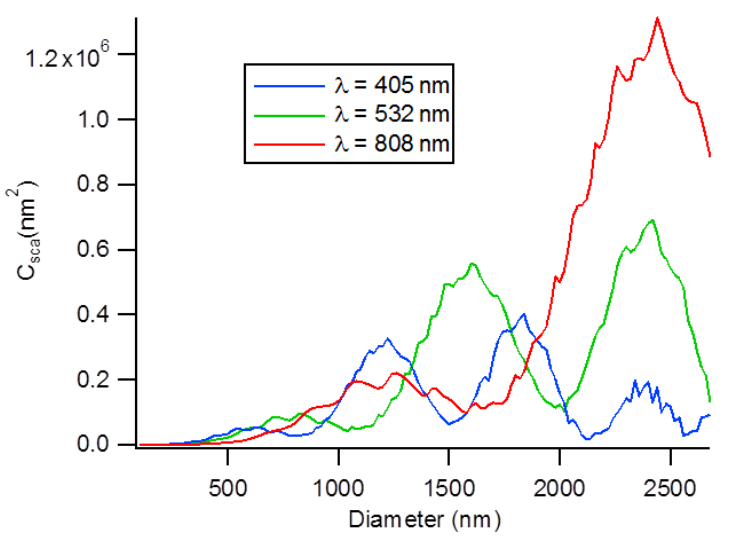

Figure 5. Values of $C_{\text {sca }}$ vs. particle diameter calculated from the scattnlay algorithm for wavelengths used in commercially available lasers. Refractive index: 1.59; collection angle: $10-12^{\circ}$.

For a given wavelength of incident light, Mie theory provides an exact solution to the scattering of light by a sphere of known size and refractive index. The scattnlay algorithm (Peña and Pal, 2009) was used to model $C_{\text {Sca }}$ for a variety of collection angles, particle sizes, and incident wavelengths. Examples of how $C_{\mathrm{Sca}}$ varies with particle size and wavelengths are demonstrated in Fig. 5. In these examples, the light collection is set at $10-12^{\circ}$ (representing detection stage 2), and the refractive index is 1.59 . The wavelengths of commercially available laser systems are plotted.

\section{Results}

In Sect. 4.1 we compare the results of laboratory measurements of the instrument performance with detection system A and detection system B in second-laser-only acquisition mode ( $E_{\text {TriggeredMS }}$ ), which showed an improve- 
ment in instrument performance when the detection system with the collimated beam was implemented. Using these results, along with a measurement of the particle beam width (Sect. 4.2), we calculated the value for the transfer function $(K)$ described in the model by the empirical measurement of the required model parameters with a $600 \mathrm{~nm}$ PSL particle. The method used for calculating the transfer function is described in Sect. 4.3.

The input of the transfer function into the numerical model of the optical detection geometry allowed the calculation of the effective detection radius $(R)$ with respect to particle diameter across the transmission range of the instrument $(0.2-$ $2.5 \mu \mathrm{m})$. The results of modelling the effect of different optical detection system design parameters on $R$ are presented in Sect. 4.4. In Sect. 4.5 we use the modelled data to explain the differences between particle size distributions measured by the LAAP-TOF and those measured by the APS in ambient data.

\subsection{Instrument performance measurements}

We directly measured the instrument performance in secondlaser-only acquisition mode ( $\left.E_{\text {TriggeredMS }}\right)$ in the laboratory by comparing size-selected number concentrations measured with a CPC with the number of mass spectra $\left(\mathrm{cm}^{-3}\right)$ generated by the LAAP-TOF. Results of this measurement using detection system A are shown in Fig. 6a. The data show a characteristically steep drop-off in $E_{\text {TriggeredMS }}$ for small particles described by others for instruments operating in a similar acquisition mode (Cziczo et al., 2003, 2006). The minimum-sized particles that could be detected with the $405 \mathrm{~nm}$ diode system were $350 \mathrm{~nm}$, and the maximum efficiency achieved was a little over 0.01 for $E_{\text {TriggeredMS }}^{600 \mathrm{~nm}}$. For particle $>600 \mathrm{~nm}$, the efficiency decreases with increasing particle size so that $E_{\text {TriggeredMS }}^{800 \mathrm{~nm}}=0.005$. This result is in good agreement with LAAP-TOF detection efficiency data recently reported by Gemayel et al. (2016), who detected a minimum particle size of $350 \mathrm{~nm}$, a peak detection efficiency of 0.025 at $450 \mathrm{~nm}$, and decrease in sensitivity to particle with diameters of $800 \mathrm{~nm}$.

To analyse the contributing factors to the reported efficiency, we examined the data for $600 \mathrm{~nm}$ spherical particles in more detail. It is well established that an aerodynamic lens can achieve an efficiency close to unity for the size range under examination here (20-600 nm) (Huffman et al., 2005; Williams et al., 2013); therefore, although the lens is uncharacterised, we assumed $E_{\mathrm{Lens}}^{600 \mathrm{~nm}}=1$. It was observed that the vast majority of PSL particles that produced an optical trigger also produced a mass spectrum so that $E_{\mathrm{Hit}}^{600 \mathrm{~nm}} \approx 1$. With reference to Eq. (1), we concluded that as a first approximation the observed performance was limited by the optical detection stage, i.e. $E_{\text {TriggeredMS }}^{600 \mathrm{~nm}} \approx E_{\text {Detect }}^{600 \mathrm{~nm}}$.

The calculated scattering cross section $\left(C_{\text {sca }}\right)$ for $405 \mathrm{~nm}$ light is plotted against particle diameter for comparison with $E_{\text {Triggerd MS }}$ in Fig. 6a. At the small particle sizes (200-
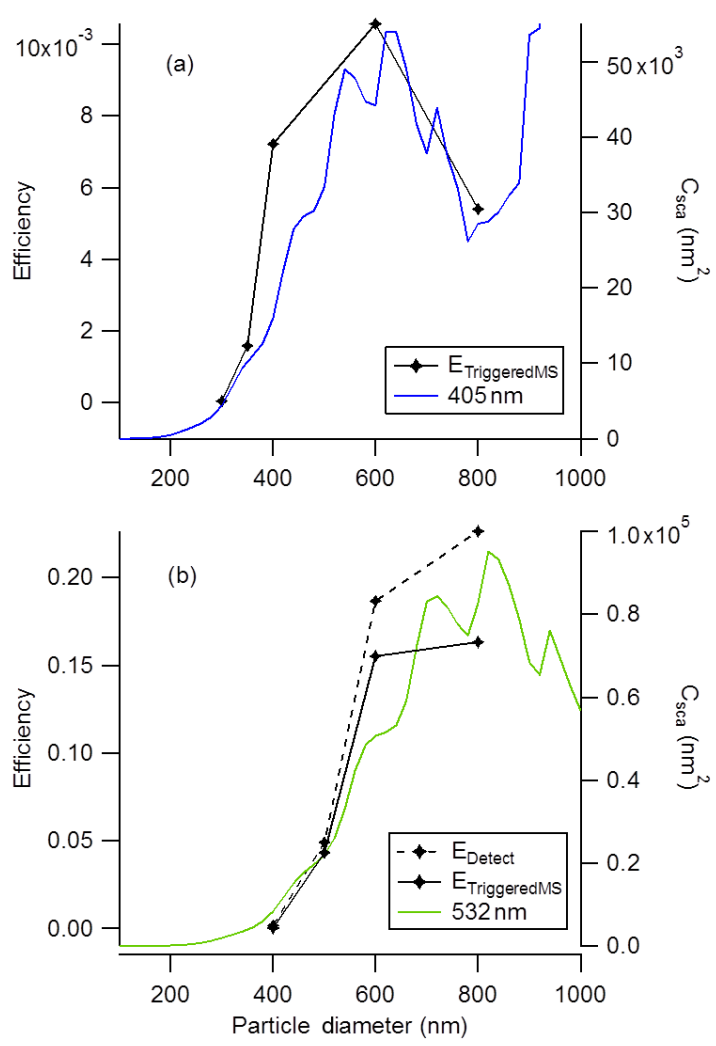

Figure 6. Instrument performance measurements in "second-laseronly" acquisition mode ( $E_{\text {TriggeredMS }}^{d}$ ). Measurements are the comparison of number concentration obtained by the CPC with the number of mass spectra $\left(\mathrm{cm}^{-3}\right)$ obtained by the LAAP-TOF when sampling size-selected laboratory-generated PSL aerosol. The scattering cross section $\left(C_{\mathrm{sca}}\right)$ for the respective wavelength is plotted for reference. (a) Detection system A with the $C_{\text {sca }}$ profile for $405 \mathrm{~nm}$ light. (b) Detection system B with the $C_{\text {sca }}$ profile for $532 \mathrm{~nm}$ light. The detection efficiency $E_{\text {Detect }}$ of detection stage 2 is also plotted in panel (b), which represents the number of trigger events generated by the optical detection system.

$600 \mathrm{~nm})$ there is a correlation between the two curves, indicating that the low size cut-off in the sampling efficiency, in this case $350 \mathrm{~nm}$, is limited by the scattering intensity of small particles. However, it is also clear that $C_{\mathrm{sca}}$ function is non-monotonic and will also affect the detection efficiency of larger particles, particularly in the region $700-900 \mathrm{~nm}$ as suggested by Gaie-Levrel et al. (2012) and Gemayel et al. (2016).

$C_{\text {sca }}$ of small particles $(200-800 \mathrm{~nm})$ at $532 \mathrm{~nm}$ also correlates with the sampling efficiency curve measured with detection system B (Fig. 6b). This method of detection laser delivery results in values of $E_{\text {TriggeredMS }}$ of an order of magnitude higher than detection system A for particles larger than $500 \mathrm{~nm}$. There is evidence that $E_{\mathrm{Hit}}<1$ with this detection geometry as a significant number of optical triggers did not produce a mass spectrum. For example $E_{\text {TriggeredMS }}^{600 \mathrm{~nm}}=0.15$ and the corresponding optical de- 


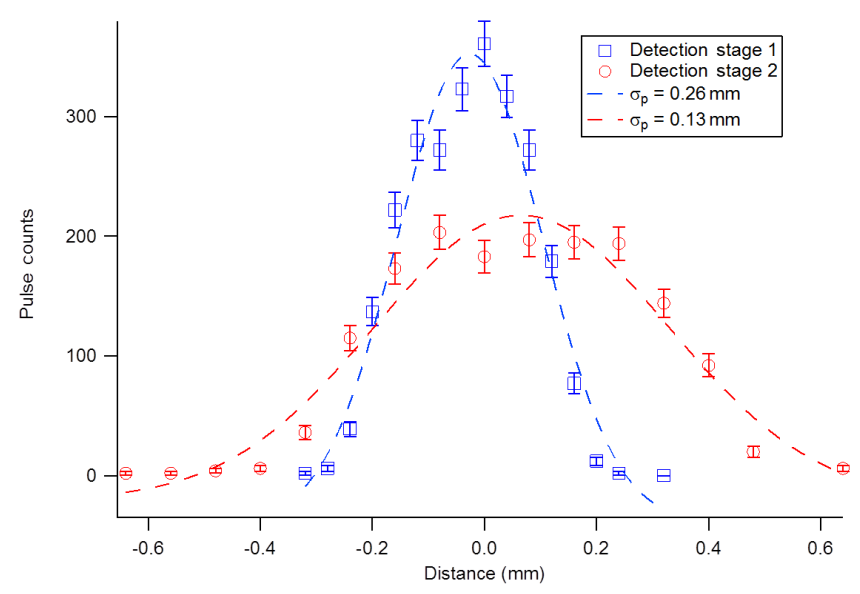

Figure 7. Gaussian particle beam profiles obtained using the optical characterisation method. Measurements were made using a beam of $600 \mathrm{~nm}$ PSL at detection stage 1 and detection stage 2 at a distance of 125 and $240 \mathrm{~mm}$ from the aerodynamic lens nozzle respectively. Error bars are $1 \sigma$ standard errors, assuming Poisson statistics.

tection efficiency $E_{\text {Detect }}^{600 \mathrm{~nm}}=0.19$, indicating that $E_{\mathrm{Hit}}^{600 \mathrm{~nm}}=$ 0.79 . The shift in the $E_{\text {TriggeredMS }}$ function with respect to particle size when changing laser wavelength confirms that a more general case $E_{\text {TriggeredMS }}^{d} \approx E_{\text {Detect }}^{d}$ for detection system $\mathrm{A}$ and that the observed $E_{\text {Detect }}^{600 \mathrm{~nm}}>E_{\text {Detect }}^{800 \mathrm{~nm}}$ is an optical detection effect and not a lens transmission effect.

\subsection{Particle beam width measurements}

Measurements of the particle beam width were made with a particle beam created from the nebulisation of $600 \mathrm{~nm}$ sized PSLs using the optical characterisation method. The resulting particle density profiles at detection stage 1 and detection stage 2 are shown in Fig. 7. Assuming the active area of detection is very small compared to the beam cross-sectional area, and that the focal point passes through the particle beam axis, a 1-D Gaussian curve fit is a sufficient approximation (Jayne et al., 2000). The beam width is estimated to be $\sigma_{\mathrm{p}}^{600 \mathrm{~nm}}=0.13 \mathrm{~mm}$ at detection stage $1(125 \mathrm{~mm}$ from the lens exit), and $\sigma_{\mathrm{p}}^{600 \mathrm{~nm}}=0.26 \mathrm{~mm}$ at detection stage 2 ( $240 \mathrm{~mm}$ from the exit of the aerodynamic lens).

\subsection{Derivation of the transfer function}

A collimated detection laser beam, whose full $1 / e^{2}$ width of $330 \mu \mathrm{m}$ (equivalent to $\sigma_{\mathrm{d}} \approx 0.0825 \mathrm{~mm}$ ) exceeds $I_{\min }$, transecting a $\sigma_{\mathrm{p}}^{600 \mathrm{~nm}}=0.26 \mathrm{~mm}$ wide particle beam would theoretically give an optical detection efficiency $E_{\text {Detect }}^{600 \mathrm{~nm}}=0.53$ (Eq. 2). This value is significantly higher than the measured value of 0.19 . The most likely explanation is that with $600 \mathrm{~nm}$ diameter spherical particles the effective detection radius $(R)$ is significantly less than the $1 / e^{2}$ beam diameter because the intensity threshold of detection is only exceeded by a portion of the Gaussian beam profile.
We used the model of the optical detection geometry to calculate the transfer function $(K)$. Using Eq. (2) and the empirically derived values $E_{\text {Detect }}^{600 \mathrm{~nm}}=0.19$ and $\sigma_{\mathrm{p}}^{600 \mathrm{~nm}}=$ $0.26 \mathrm{~mm}$, the calculated value of $R_{\text {detect }}^{600}=0.057 \mathrm{~mm}$. From Eq. (3), this value of $R$ in a detection beam width $\sigma_{\mathrm{d}}=0.0825 \mathrm{~mm}$ corresponds to laser beam intensity $\left(I_{\min }\right)$ of $1.1 \mathrm{~W} \mathrm{~mm}^{2}$. Using Eq. (4) and a $C_{\text {sca }}$ value of $5.066 \times 10^{-8} \mathrm{~mm}^{-2}$ derived from a scattnlay calculation, the value of the transfer function $(K)$ is $5.59 \times 10^{-8} \mathrm{~W}$.

The calculation of the transfer function allows $R$ to be plotted as a function of particle size across the particle transmission size range by calculating $I_{\min }$ for any particle diameter using the corresponding value $C_{\mathrm{sca}}$ in Eq. (3).

\subsection{Estimations of the effective detection beam radius with selected wavelengths, collection angles, and signal-to-noise conditions.}

The model allows for the evaluation of the effective detection radius $(R)$ with respect to particle size with selected optical detection stage design parameters. Results of modelling the design parameters used in detection system B with PSL particles across the theoretical transmission range of the aerodynamic lens are represented by the solid green line in Fig. 8a, b, and c. The design parameters used are wavelength $=532 \mathrm{~nm}$, collection angle $=10-12^{\circ}$, detection beam width $\sigma_{\mathrm{d}}=0.0825 \mathrm{~mm}$, and a refractive index of 1.59 for PSL was used in the scattnlay model for Mie scattering. The data predict a rapid drop-off in $R$ when the particle diameter is less than $\approx 550 \mathrm{~nm}$. Oscillations of the scattering phase function with respect to particle size impact $R$ across the transmission range, with distinct minima observed at 1 and $2 \mu \mathrm{m}$ particle diameter.

The effect of changing the detection laser wavelength is demonstrated in Fig. 8a. The model predicts that using a detection system laser wavelength of $405 \mathrm{~nm}$ results in a lower particle size cut-off $(R=0)$ as expected. In general, shorter wavelengths produce deeper oscillations at a higher frequency than longer wavelengths. A wavelength of $808 \mathrm{~nm}$ produces the most stable profile but comes at the expense of the small particle detection, which drops-off at $700 \mathrm{~nm}$.

The effect of light collection angle was modelled by changing the input parameters to the scattnlay algorithm. Light collected over $10-170^{\circ}$, which is similar to the collection angle of some elliptical mirrors (Pratt et al., 2009; Brands et al., 2011), produces a smoother profile with a lower particle size cut-off than the narrow angles represented by the LAAP-TOF detection system (Fig. 8b). This is because collecting more light increases the integrated phase function and requires less intensity in the detection beam in order to exceed $I_{\min }$. The variation in $R$ stabilises near the maximum attainable value if the value of $R$ is close to the $3 \sigma_{\mathrm{p}}$ detection beam width. Note that light collection at detection stage 1 (front) in the LAAP-TOF, represented in Fig. 8b at an angle of $13-15^{\circ}$, predicts blind spots in the transmission range. 

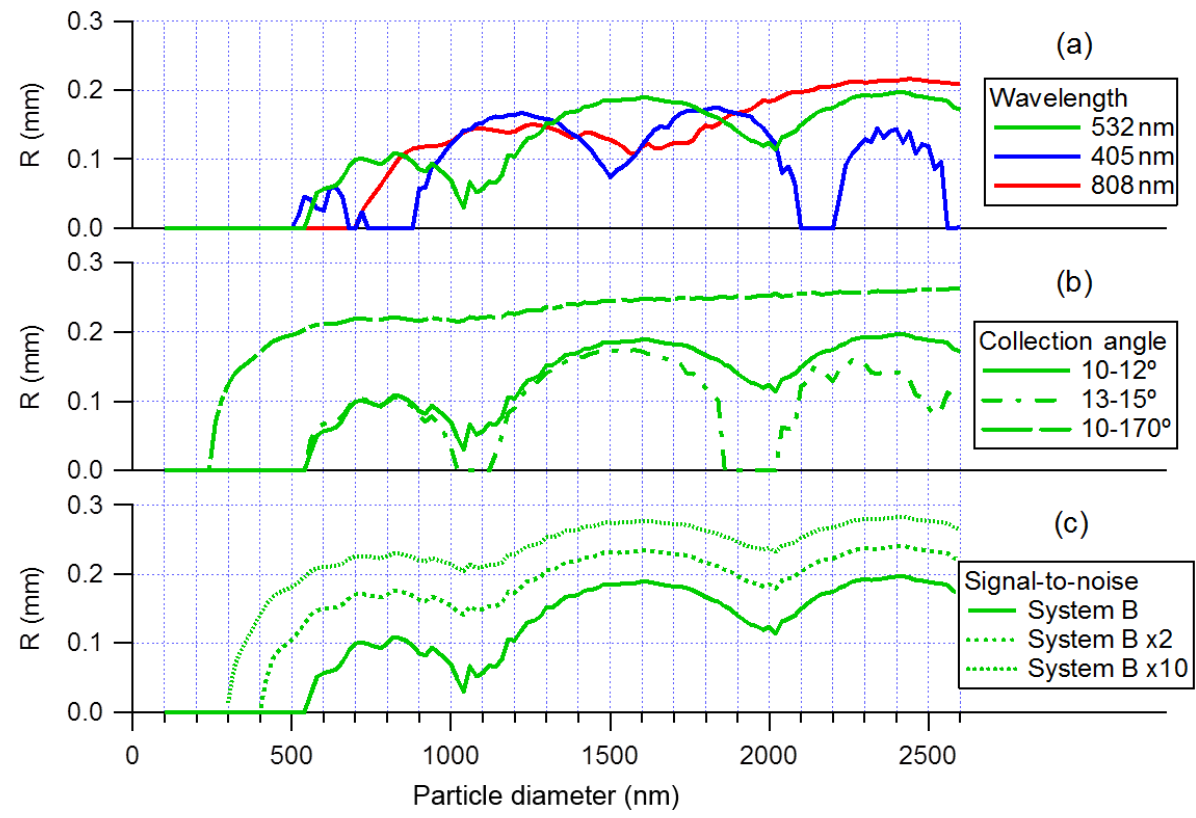

Figure 8. Results of modelling the optical detection geometry with selected design configurations, showing the calculated effective detection radius $(R)$ with respect to particle diameter for PSL particles (refractive index $=1.59$ ). Profiles are modelled by changing only one parameter with respect to the design of detection system $\mathrm{B}$, which is shown as a solid green line in each plot for reference. The reference configuration of detection system $B$ is $\sigma_{\mathrm{d}}=0.0825 \mathrm{~mm}$, wavelength $=532 \mathrm{~nm}$, and a light collection angle of $10-12^{\circ}$. (a) The effect of using detection laser wavelengths 405 and $808 \mathrm{~nm}$, (b) the effect of light collection angle of 13-15 and 10-170 , (c) the effect of improving the signal-to-noise ratio of detection system $B$ twofold $(\times 2)$ and 10 -fold $(\times 10)$.

This is not thought to be the actual case for the system as the front optics have a lower background noise than the rear optics and so will have a lower value of the transfer function, producing smaller amplitude variation in the profile.

Adjusting the value of the transfer function in the model allows for the simulation of the impact of signal-to-noise ratio on $R$. This is important as signal-to-noise ratio can be affected by alignment of the system during set-up as well as the design of the detection stage. Increasing the signal-tonoise ratio by a factor of 2 and by a factor of 10 is simulated in Fig. 8c. In general, a larger signal-to-noise ratio produces a larger $R$ over the transmission range and reduces the low particle cut-off size. However, it does not reduce the amplitude of oscillation in the $R$ function as much as changing the collection angle.

The choice of optical lens determines the width of the beam waist of the collimated beam. With a set laser power output, increasing the beam waist width has the effect of reducing the intensity at a given radial distance from the beam axis. Results of modelling of $I_{\min }$ with respect to $\sigma_{\mathrm{d}}$ shown in Fig. 4 demonstrate that a common maximum $R$ does not exist for the variable $I_{\min }$. This indicates a particle size dependence in the optimal $\sigma_{\mathrm{d}}$ value with this detection geometry. This effect is quantified in Fig. 9a, which shows the variation in $R$ as a function of $\sigma_{\mathrm{d}}$ and particle diameter. Small focal points give the least variation with respect to particle size but produce a relatively small effective beam radius $(R<0.1 \mathrm{~mm})$. Values of $R$ can be produced that exceed $0.6 \mathrm{~mm}$ but come at the expense of very high variation with respect to particle size that causes blind areas at 1000 and $2000 \mathrm{~nm}$ particle diameter due to an effective detection radius of $0 \mathrm{~mm}$.

\subsection{Comparison of the estimated effective beam radius with ambient measurements of particle size distributions}

The results of modelling the effective detection radius are compared to the particle counting statistics from the measurement of polydisperse aerosol populations at the ambient measurement site. The size-resolved composition measurement of 99463 particles obtained over a 7-day period were analysed using the LAAP-TOF Data Analysis tool (v1.0.0, AeroMegt $\mathrm{GmbH})$. In order to analyse the particle counting statistics of the principal particle composition types, the mass spectra were placed into six classes using the fuzzy cmean clustering algorithm provided in the software. An Epsilon target value of $1 e^{-7}$ and a fuzzyfier value of 1.2 were chosen. Mass spectra representing the cluster centres of each class are shown in Fig. 10.

The first class (Fig. 10a) is identified as silicate and contains characteristic markers of sodium $(m / z 23)$, aluminium $(m / z 27)$, silicon $(m / z 28)$, potassium $(m / z 39)$, and iron $(\mathrm{m} / z$ 56) in positive-ion and oxides of silicon $(\mathrm{m} / z-60$ 

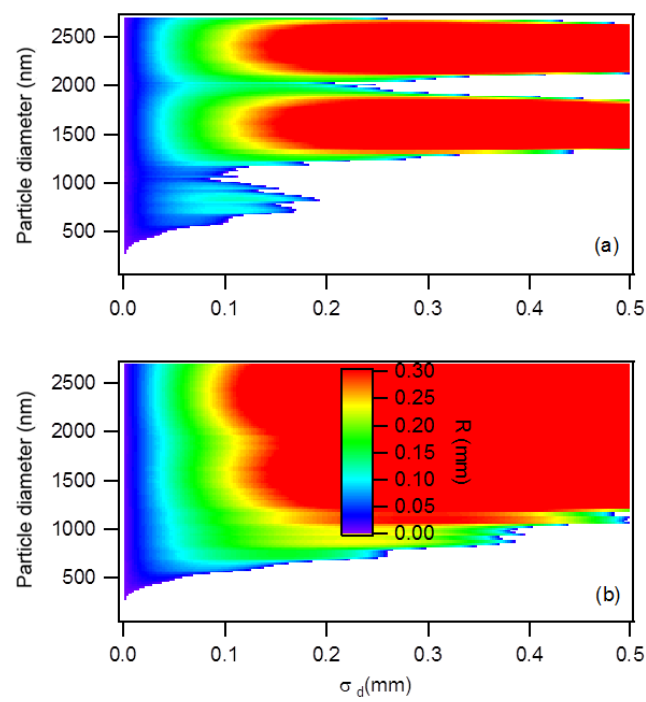

Figure 9. Model of the effective detection beam radius as a function of particle size and collimated beam waist size. (a) A detection system comprising $300 \mathrm{~mW}$ and a wavelength of $532 \mathrm{~nm}$, with light collection $10-12^{\circ}$, and (b) a detection system comprising equally mixed 532 and $808 \mathrm{~nm}$ laser sources.

$\left.\left[\mathrm{SiO}_{2}\right]^{-}, m / z-76\left[\mathrm{SiO}_{3}\right]^{-}\right)$in negative-ion mode. In addition, there are markers for chlorine $(m / z-35,-37)$, nitrate $(\mathrm{m} / z-46)$, and sulphate $(\mathrm{m} / \mathrm{z}-97)$, indicating that these silicate mineral particles are internally mixed with secondary species. The second class (Fig. 10b) is dominated by the same secondary species in negative-ion mode and shows the presence of ammonium $(\mathrm{m} / \mathrm{z} 18)$, nitrate $(\mathrm{m} / \mathrm{z} 30)$, and carbon clusters $(m / z, 12,24,36)$ in positive-ion mode. We have designated the name carbonaceous/secondary to the second particle class.

The remaining four particle classes (Fig. 10c-f) are dominated by potassium $(\mathrm{m} / \mathrm{z} 39)$, sodium $(\mathrm{m} / \mathrm{z} 23)$, chlorine $(\mathrm{m} / \mathrm{z}-35,-37)$, and sodium chloride clusters $(\mathrm{m} / \mathrm{z} 81,83$ $\left.\left[\mathrm{Na}_{2} \mathrm{Cl}\right]^{+}, m / z-93,-95\left[\mathrm{NaCl}_{2}\right]^{-}\right)$. We identified these particles as sea salt class (1-4). The presence of a peak at $m / z 24,40$, and 82 in sea salt class 3 and 4 is the result of spectral peak broadening and peak position shift in the raw positive-ion spectra. The presence of water in these particles $\left(m / z-16\right.$ and -17 , and $m / z, 62\left[\mathrm{Na}_{2} \mathrm{O}\right]^{+}$and $\left.63\left[\mathrm{Na}_{2} \mathrm{OH}\right]^{+}\right)$ indicates that these particles are likely to be aqueous droplets (Dall'Osto et al., 2004). As the differentiation of these sea salt classes by the fuzzy clustering is likely to result from changes in instrument function rather than compositional differences in the particle, we combined all four classes into one sea salt class when considering particle counting statistics.

A $10 \mathrm{~min}$ averaged time series of the clustered particle number concentrations over a 7-day period is shown in Fig. 11 alongside number concentration reported by the APS system in the size range $0.5-2.46 \mu \mathrm{m}$ aerodynamic diameter. The LAAP-TOF total number concentration is approximately 2 order of magnitude lower than that reported by

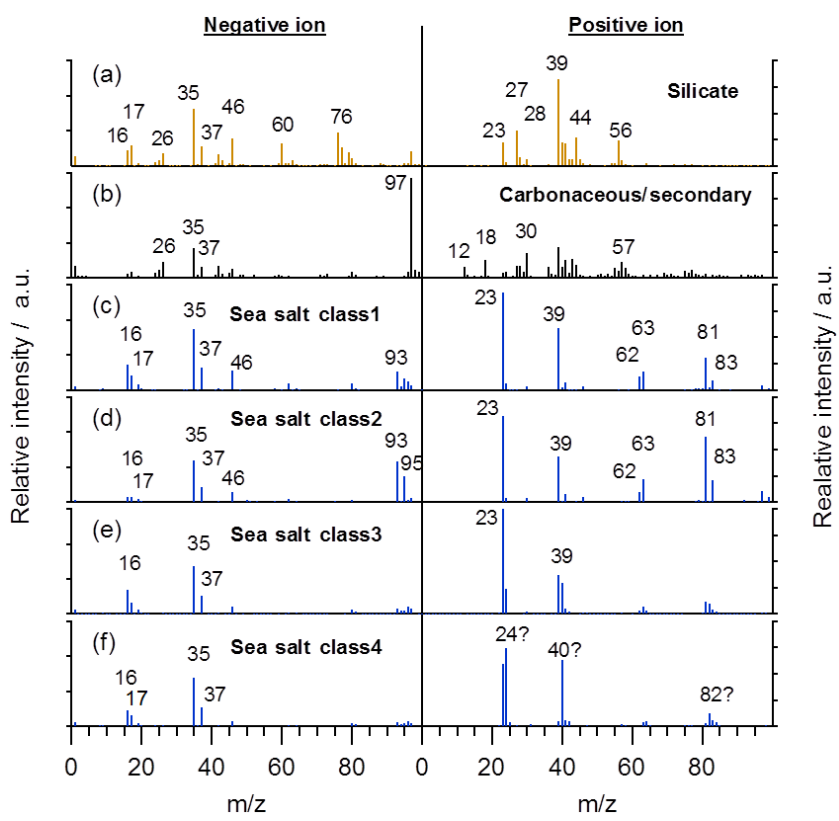

Figure 10. Representative spectral patterns of the cluster centres (af) produced by fuzzy c-means cluster analysis of ambient data acquired at Praia, Cabo Verde, during the ICE-D campaign in $\mathrm{Au}-$ gust 2015 .

the APS. The time series trends are generally well correlated over the first 4 days, with divergence occurring after the arrival of silicate dust from the Sahara around midnight on 11 August 2015, indicating that the LAAP-TOF may be under-counting the silicate class of particles with respect to the sea salt class of particle. Overall, the combined sea salt particles class accounted for $86 \%$ of the particles analysed by the LAAP-TOF during this sampling period (Fig. 11 inset).

The dominance of the sea salt class of particle in the LAAP-TOF measurement is also evident in the vacuum aerodynamic size distributions displayed in Fig. 12a. The size distribution of the sea salt class accounts for most of the observed sized distribution of the LAAP-TOF total number concentration, with the contribution from the silicate and carbonaceous/secondary classes only significant $<1000 \mathrm{~nm}$. The aerodynamic size distribution reported by the APS shows a relatively broad mode centred on $\approx 1200 \mathrm{~nm}$ that is more similar to the silicate and carbonaceous/secondary particle classes than to the sea salt class. This supports the hypothesis that the sea salt class is over-represented in the relative particle number concentration measured by the LAAPTOF, although differences in the measurement techniques of the two instruments must be considered.

A significant difference in the size distributions is the local minimum at $\approx 1000 \mathrm{~nm}$ in particle concentration observed in the silicate and carbonaceous/secondary classes that are not present in the APS distribution. Comparison with the modelled effective detection radius $(R)$ in Fig. 12b shows that 


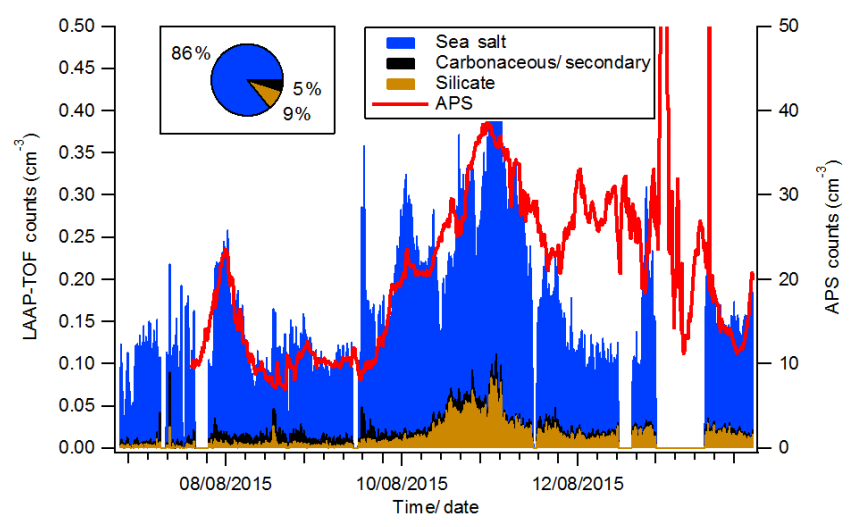

Figure 11. Time series of averaged number concentrations measured by the LAAP-TOF and APS for a 7-day period at Praia, Cabo Verde, during the ICE-D campaign. Concentrations are calculated from 10 min averaged number counts at a flow rate of 0.078 and $1 \mathrm{~L} \mathrm{~min}^{-1}$ for the LAAP-TOF and APS respectively. The calculated concentrations of sea salt, carbonaceous/secondary material, and silicates (as determined by fuzzy c-means clustering) are stacked in the time series so that total number concentration measured by the LAAP-TOF is represented by the top of the filled area. The relative number concentrations of the main particle classes are displayed in the inset pie chart.

this local minimum in the size distribution coincides with a local minimum in the $R$ profile. However, this minimum is not observed in the size distribution for the sea salt class. The light-scattering properties of marine aerosol are known to vary considerably with composition and humidity (Tang et al., 1997). If the value of $R$ with respect to particle diameter is modelled with a particle refractive index of an aqueous sea salt particle (1.33), a significantly different $R$ profile is predicted that does not contain a local minimum at around $1000 \mathrm{~nm}$ (Fig. 12c).

\section{Discussion}

In the model of the optical detection geometry we describe the optical detection efficiency in terms of the overlap of the detection beam with the particle beam. The Gaussian profile of the detection laser beam results in a particle-dependent variation in the effective beam width, which we term the effective detection radius $(R)$. For a certain instrument design, $R$ is a function of the scattering cross section of the particle, resulting in a particle size dependence. Instrument design parameters such as the detection laser wavelength, the light collection angle, and the signal-to-noise level in the detection stage have a strong influence on $R$.

Ambient measurements demonstrate the impact that the variation in the effective detection radius may have on the data. Comparison with the size distribution measured with the APS suggests that a size-dependent detection bias is imposed on the measured size distributions. Furthermore, the
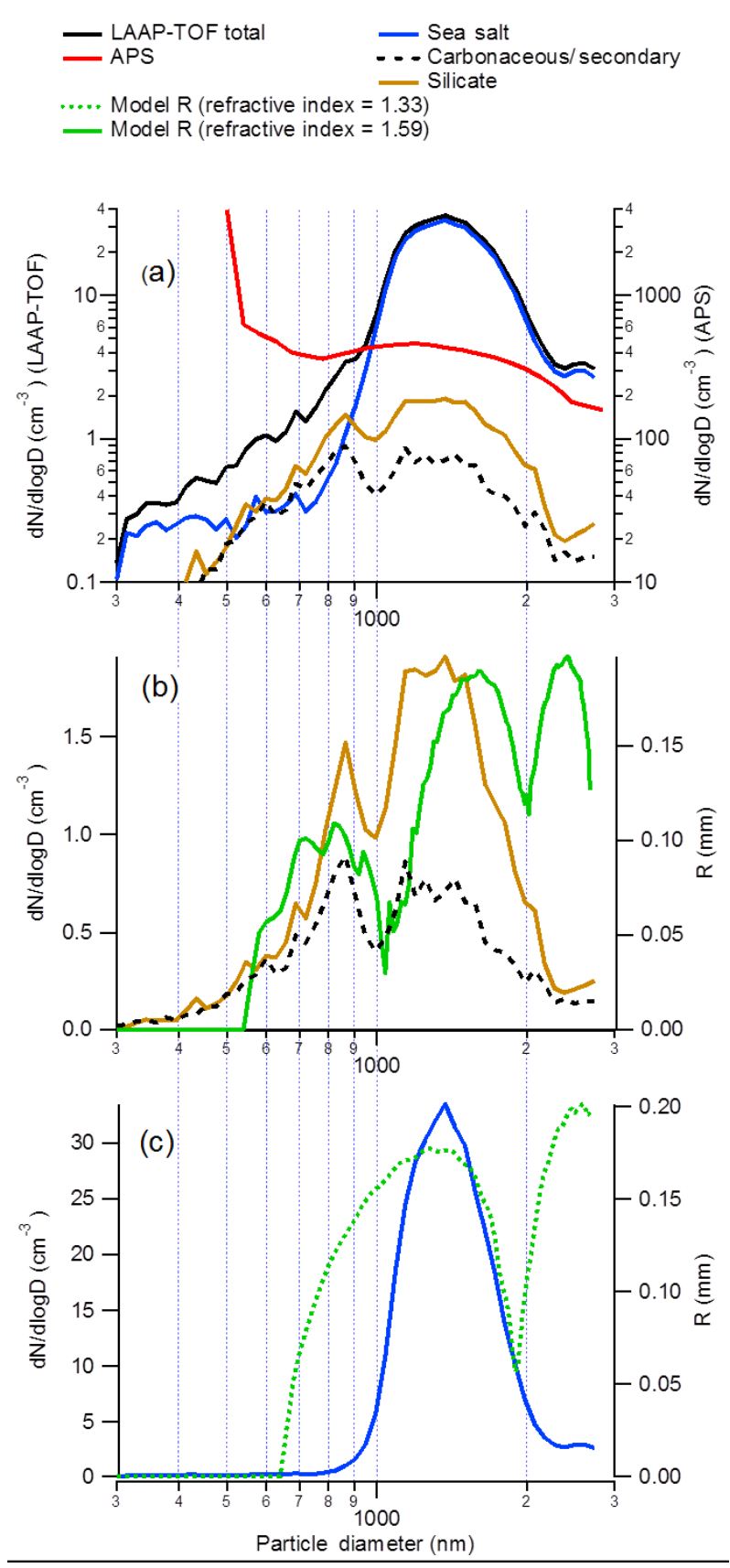

Figure 12. Particle size distributions measured by the LAAP-TOF and an aerodynamic particle sizer (APS) at Praia, Cabo Verde, during the ICE-D campaign. (a) The vacuum aerodynamic diameter size distribution of the total number concentration and main particle composition classes measured by the LAAP-TOF compared to the aerodynamic size distribution measured by the APS. (b) The carbonaceous/secondary and silicate size distributions compared to the modelled effective detection radius of optical detection stage 2 (refractive index: 1.59; collection angle: $10-12^{\circ}$ ). (c) The sea salt size distributions compared to the modelled effective detection radius of the second optical detection stage (refractive index: 1.33; collection angle: $10-12^{\circ}$ ). 
particle refractive index appears to have a strong influence on this detection bias, which further complicates the interpretation of size distributions. Overall, the LAAP-TOF reports particle concentration in the size range $0.5-2.5 \mu \mathrm{m}$, which is approximately 2 orders of magnitude lower than those reported by the APS. Much of this deficit in particle counting may be accounted for by composition-dependent ionisation efficiency on the ion source and a reduction in optical detection efficiency due to particle beam divergence. However, the optical detection efficiency must also be influenced by the size-dependent variation in the effective detection radius. For example, the coincidence of a maximum in $R$ with the mode size of the sea salt class of particles will enhance the number counting statistics of those particle types.

Optical detection of particles in SPMS has been the focus of much research (Murphy, 2007). Early instruments used fibre optics to guide scattered light to PMTs for detection (Prather et al., 1994; Hinz and Kaufmann, 1996). The introduction of an ion source extraction plate fashioned into an elliptical mirror (Murphy and Thomson, 1995) allowed light to be collected over a wider solid angle within the ion source whilst maintaining relatively high hit rates, but this approach is not amenable to a bipolar TOF analyser due to extraction field distortion. The removal of the detection optics from the ion source region permitted a more complete elliptical mirror to be used (Gard et al., 1997) but required a more complex trigger system to ensure the UV ablation laser hits particles travelling at different velocities.

The aim of using elliptical mirrors is to collect as much scattered light as practicable over a wide solid angle. The benefit of this approach is demonstrated in the model results that calculate $R$ to be close to the $3 \sigma_{\mathrm{d}}$ width across much of the transmission range. Authors have reported detection efficiencies of 0.5-1 for instruments using this type of collection optics (Su et al., 2004; Zelenyuk and Imre, 2005; Zelenyuk et al., 2009; Brands et al., 2011) over selected size ranges, typically $200-600 \mathrm{~nm}$. Hit rates are generally lower with instruments that do not trigger in the ion source, and overall sampling efficiency is rarely reported in the literature.

An ideal instrument design would have optical detection in the ion source of a bipolar TOF while maintaining the optical detection efficiency of an elliptical mirror. This is very difficult to achieve in practice. The compact design of the light collection optics in the LAAP-TOF allows for the detection stage to be placed in the ion source but collects light over a very narrow solid angle. Our initial laboratory studies with detection system A showed a low detection efficiency in the size range $300-800 \mathrm{~nm}$, which was a limiting factor in the overall instrument performance.

Laser diode light sources have relatively low power and produce a relatively divergent beam that can be difficult to focus with a single lens. The implementation of a $532 \mathrm{~nm}$ Nd:YAG laser with high pointing stability allowed for singlemode fibre coupling and efficient collimation to a larger beam waist diameter compared to the focal point of de- tection system A. The implementation of detection system $B$ resulted in over an order-of-magnitude improvement in $E_{\text {TriggeredMS }}$ compared to detection system A, but it came at the expense of a slightly larger particle size cut-off. Larger beam diameters have the potential to increase the detection efficiency for some particle sizes. However, modelling of the effective beam diameter shows that, for a set laser power output, the optimum detection laser beam width is particle size dependent (Fig. 9a). The particle size distribution of the target application must be considered when choosing the output power and focussing characteristics of the detection laser system if using light collection optics with a narrow collection angle.

Optical particle detection is an established technique in instruments dedicated to measuring particle size distributions of ambient aerosol populations (Baumgardner et al., 2011). The smoothing of Mie scattering oscillation is a design requirement when accurate particle size measurement requires a near-monotonic response in pulse magnitude with respect to particle diameter (McMurry, 2000). Instruments utilising monochromatic laser source require a wide collection angle, whereas a monotonic response has been reported for a nearforward scattering instrument using an incandescent (whitelight) source (Heim et al., 2008).

A detection laser consisting of mixed wavelengths may be beneficial to the near-forward light collection system utilised in the LAAP-TOF. The Mie theory model (Fig. 5) indicates that $532 \mathrm{~nm}$ may complement $808 \mathrm{~nm}$ by covering the deep oscillation in the profile. The mixing of light from two distinct sources is possible with a fibre-coupled system. Figure $9 \mathrm{~b}$ shows an example of the modelled $R$ with respect to particle size and detection beam width using equal powered 532 and $808 \mathrm{~nm}$ wavelength sources whilst maintaining the signal-to-noise characteristics of detection system B. This model shows less variation in $R$ with respect to particle size and offers the possibility of using larger $\sigma_{\mathrm{d}}$, which would improve the overall sampling efficiency.

\section{Conclusions}

A custom detection laser system consisting of a highpowered fibre-coupled Nd:YAG solid-state laser with a collimated beam was implemented in a LAAP-TOF singleparticle mass spectrometer without major modifications to instrument geometry. The new laser system resulted in an order-of-magnitude improvement in sensitivity to spherical particles in the size range $500-800 \mathrm{~nm}$ compared to a focussed $405 \mathrm{~nm}$ laser diode system. A numerical model is presented that allows for a general evaluation of how beam width, wavelength, and light collection geometry affect the particle detection efficiency of the optical detection stage. We used the model to explain number counting bias in an ambient data set. 
The laser intensity encountered by a particle in a collimated laser beam is a function of its position within the Gaussian intensity distribution with respect to the laser beam axis. A transfer function was calculated in order to quantify the minimum intensity requirement which defines an effective detection radius $(R)$ that is a function of the scattering cross section $\left(C_{\text {sca }}\right)$ of the particle. The model predicts that $C_{\text {sca }}$ controls the limit of the detection in terms of particle size as expected. However, if light is collected over a narrow collection angle, Mie interference patterns result in an oscillation of $R$ with respect to particle size across the transmission range $(0.2-2.5 \mu \mathrm{m})$ of the LAAP-TOF, resulting in large particle-size-dependent variation in detection efficiency. We compare the model prediction with an ambient data set acquired during the ICE-D project, a multi-platform field campaign based at the Cabo Verde islands in August 2015. The model is used to partly explain a detection bias towards sea salt particles with an aerodynamic size mode of $\approx 1.5 \mu \mathrm{m}$. We also show that the detection bias imposes itself on the measured aerodynamic size distribution as determined by the instrument, an effect that must be considered when interpreting the data.

Modelling of the effective detection radius shows that for a set laser power output the optimum detection laser beam width is also particle size dependent. The particle size distribution of the target application must be considered when choosing the output power and focussing characteristics of the detection laser system if using light collection optics with a narrow collection angle. Variations in the effective detection radius could be minimised by collecting light over a wider angle or by mixing laser wavelengths. The stabilisation of $R$ with respect to particle diameter would result in more accurate aerodynamic size distribution measurements and reduce the variation in particle number concentration measurements of different particle size, shape, and refractive index. A more rigorous evaluation of the effective of particle size and morphology on the overall sampling efficiency of the instrument would require a model of the aerodynamic lens characteristics in order to constrain particle beam divergence. The effect of particle beam divergence on both the variation and absolute sampling efficiency could be improved by reducing the length of the particle flight path by shortening the vacuum housing.

\section{Data availability}

Laboratory-acquired data used to inform the model of the the effective beam radius are available from the author by request. 


\section{Appendix A: List of symbols}

\begin{tabular}{|c|c|}
\hline Symbol & Description \\
\hline$d$ & Particle diameter. \\
\hline$\sigma_{\mathrm{p}}$ & Particle beam width. \\
\hline$\sigma_{\mathrm{d}}$ & Detection beam width. \\
\hline$C_{\text {sca }}$ & Scattering cross section. \\
\hline$R$ & Active radius of detection. \\
\hline$I_{\min }$ & $\begin{array}{l}\text { Minimum intensity threshold re- } \\
\text { quired to produce enough scattered } \\
\text { light to register a particle event. }\end{array}$ \\
\hline$K$ & $\begin{array}{l}\text { Transfer function of the optical de- } \\
\text { tection stage. }\end{array}$ \\
\hline$E_{\text {Lens }}$ & $\begin{array}{l}\text { Transmission efficiency of the aero- } \\
\text { dynamic lens. }\end{array}$ \\
\hline$E_{\text {Hit }}$ & Hit rate efficiency. \\
\hline$E_{\text {Detect }}$ & $\begin{array}{l}\text { The particle detection efficiency of } \\
\text { the optical detection stage. }\end{array}$ \\
\hline$E_{\mathrm{Geom}}$ & $\begin{array}{l}\text { Geometric overlap of the excimer } \\
\text { laser pulse with the particle beam. }\end{array}$ \\
\hline$E_{\text {Temp }}$ & $\begin{array}{l}\text { Temporal overlap of the excimer } \\
\text { laser pulse with a particle in the } \\
\text { particle beam. }\end{array}$ \\
\hline$E_{\text {Ion }}$ & $\begin{array}{l}\text { Ionisation efficiency of the excimer } \\
\text { laser pulse with respect to the } \\
\text { particle composition. }\end{array}$ \\
\hline$E_{\text {AutoMS }}$ & $\begin{array}{l}\text { Instrument sampling efficiency in } \\
\text { auto-triggering acquisition mode. } \\
\text { The excimer laser is firing at a set } \\
\text { repetition rate. }\end{array}$ \\
\hline$E_{\text {TriggeredMS }}$ & $\begin{array}{l}\text { Instrument sampling efficiency } \\
\text { in second-laser-only acquisition } \\
\text { mode. } \\
\text { The excimer laser is fired by a trig- } \\
\text { ger from the second detection stage. }\end{array}$ \\
\hline$E_{\text {SizedMS }}$ & $\begin{array}{l}\text { Instrument sampling efficiency in } \\
\text { both-lasers acquisition mode. } \\
\text { The instrument actively sizes and } \\
\text { requires a trigger from both detec- } \\
\text { tion stages. }\end{array}$ \\
\hline
\end{tabular}

\section{Appendix B: Detailed description of detection systems}

Detection system A comprises a compact $450 \mathrm{~mW}$ Opnext diode module (HL40023MG, Thorlabs) mounted in a threaded copper tube and fitted to an adjuster assembly to produce a cw laser beam of $405 \mathrm{~nm}$ wavelength orthogonal to the particle beam axis (Fig. 2a). The adjuster assembly incorporates a focussing lens to create a beam with a $D 4 \sigma$ (second moment width) focal point diameter of $51.2 \mu \mathrm{m}$ measured with a beam profiler at a focal length of $50 \mathrm{~mm}$. The power output of the system can be adjusted by varying the drive to the diode module. The position of the focal point relative to the particle beam can be adjusted by moving the whole adjuster assembly relative to the vacuum housing in the horizontal $X$ and $Y$ directions and varying the focal length in the $Z$ direction.

Detection system B comprises a $1 \mathrm{~W}$ GEM $532 \mathrm{~nm}$ Nd:YAG laser (Laser Quantum Ltd) with divergence $<0.8 \mathrm{mrad}$, pointing stability $<10 \mu \mathrm{rad} /{ }^{0} \mathrm{C}$, and a beam quality factor $\left(M^{2}\right)<1.1$, enabling the beam to be efficiently launched into a single-mode fibre and focussed into a collimated beam with just one lens. An aspheric fiberport (model PAF-X-2A, Thorlabs) with an output $1 / e^{2}$ waist diameter of $330 \mu \mathrm{m}$ and a divergence of $1.75 \mathrm{mrad}$ was chosen to collimate the beam. A maximum waist distance of $96 \mathrm{~mm}$ ensured the beam remained collimated at the light collection optics, thereby reducing background noise. The fiberport lens has an input mode field diameter (MFD) of $3.5 \mu \mathrm{m}$. The adjustable fiberport allows for precise positioning of the lens for efficient collimation and allows the beam to be steered through the spatial filters (Fig. 2b). Spatial filtering is required to clean up the beam profile and reduce background noise. A $500 \mu \mathrm{m}$ orifice is placed at the bottom of the optical stack, and the collimated beam can be accurately positioned through the pin hole using the steering on the fiberport. Light scattering from the pin hole is reduced by blackening the metallic orifice with Aquadag and introducing an intermediate $400 \mu \mathrm{m}$ orifice that is aligned to the beam axis beam using an $X_{-}$ $Y$ translator. The optical stack can be aligned on the bench before being fitted to the instrument and aligned to the lowest noise position. A N-BK7 coated laser window (Thorlabs) was used to seal the vacuum. 
Acknowledgements. This work was supported by a $\mathrm{PhD}$ studentship awarded to N. Marsden by the Natural Environment Research Council (NERC). Field measurements made during the ICE-D campaign were funded by NERC grant NE/M00195/1. We would like to thank Alisdair Macpherson of the Photon Science Institute at the University of Manchester for his technical support.

Edited by: J. Schneider

Reviewed by: two anonymous referees

\section{References}

Allen, J. O., Fergenson, D. P., Gard, E. E., Hughes, L. S., Morrical, B. D., Kleeman, M. J., Gross, D. S., Gälli, M. E., Prather, K. A., and Cass, G. R.: Particle detection efficiencies of aerosol time of flight mass spectrometers under ambient sampling conditions, Environ. Sci. Technol., 34, 211-217, 2000.

Baumgardner, D., Brenguier, J., Bucholtz, A., Coe, H., DeMott, P., Garrett, T., Gayet, J., Hermann, M., Heymsfield, A., Korolev, A., Krämer, M., Petzold, A., Strapp, W., Pilewskie, P., Taylor, J., Twohy, C., Wendisch, M., Bachalo, W., and Chuang, P.: Airborne instruments to measure atmospheric aerosol particles, clouds and radiation: A cook's tour of mature and emerging technology, Atmos. Res., 102, 10-29, doi:10.1016/j.atmosres.2011.06.021, 2011.

Boucher, O., Randall, P., Artaxo, P., Bretherton, C., Feingold, G., Forster, P., Kerminen, V., Kondo, Y., Liao, H., Lohmann, U., Rasch, P., Satheesh, S, K., Sherwood, S., Stevens, B., and Zhang, X. Y.: Clouds and Aerosols, Climate Change 2013: The Physical Science Basis. Contribution of Working Group I to the Fifth Assessment Report of the Intergovernmental Panel on Climate Change, 2013.

Brands, M., Kamphus, M., Böttger, T., Schneider, J., Drewnick, F., Roth, A., Curtius, J., Voigt, C., Borbon, A., Beekmann, M., Bourdon, A., Perrin, T., and Borrmann, S.: Characterization of a Newly Developed Aircraft-Based Laser Ablation Aerosol Mass Spectrometer (ALABAMA) and First Field Deployment in Urban Pollution Plumes over Paris During MEGAPOLI 2009, Aerosol Sci. Tech., 45, 46-64, doi:10.1080/02786826.2010.517813, 2011.

Cziczo, D. J., DeMott, P. J., Brock, C., Hudson, P. K., Jesse, B., Kreidenweis, S. M., Prenni, A. J., Schreiner, J., Thomson, D. S., and Murphy, D. M.: A Method for Single Particle Mass Spectrometry of Ice Nuclei, Aerosol Sci. Tech., 37, 460-470, doi:10.1080/02786820300976, 2003.

Cziczo, D. J., Thomson, D. S., Thompson, T. L., DeMott, P. J., and Murphy, D. M.: Particle analysis by laser mass spectrometry (PALMS) studies of ice nuclei and other low number density particles, Int. J. Mass Spectrom., 258, 21-29, doi:10.1016/j.ijms.2006.05.013, 2006.

Dall'Osto, M., Beddows, D., Kinnersley, R. P., Harrison, R. M., Donovan, R. J., and Heal, M. R.: Characterization of individual airborne particles by using aerosol time-of-flight mass spectrometry at Mace Head, Ireland, J. Geophys. Res.-Atmos., 109, D21302, doi:10.1029/2004JD004747, 2004.

Dall'Osto, M., Harrison, R. M., Highwood, E. J., O’Dowd, C., Ceburnis, D., Querol, X., and Achterberg, E. P.: Variation of the mixing state of Saharan dust particles with atmospheric transport, Atmos. Environ., 44, 3135-3146, 2010.

Dall'Osto, M., Hellebust, S., Healy, R. M., O'Connor, I. P., Kourtchev, I., Sodeau, J. R., Ovadnevaite, J., Ceburnis, D., O'Dowd, C. D., and Wenger, J. C.: Apportionment of urban aerosol sources in Cork (Ireland) by synergistic measurement techniques, Sci. Total Environ., 493, 197-208, 2014.

Erdmann, N., Dell'Acqua, A., Cavalli, P., Grüning, C., Omenetto, N., Putaud, J.-P., Raes, F., and Dingenen, R. V.: Instrument Characterization and First Application of the Single Particle Analysis and Sizing System (SPASS) for Atmospheric Aerosols, Aerosol Sci. Tech., 39, 377-393, doi:10.1080/027868290935696, 2005.

Fitzgerald, E., Ault, A. P., Zauscher, M. D., Mayol-Bracero, O. L., and Prather, K. A.: Comparison of the mixing state of long-range transported Asian and African mineral dust, Atmos. Environ., $115,19-25,2015$.

Formenti, P., Schütz, L., Balkanski, Y., Desboeufs, K., Ebert, M., Kandler, K., Petzold, A., Scheuvens, D., Weinbruch, S., and Zhang, D.: Recent progress in understanding physical and chemical properties of African and Asian mineral dust, Atmos. Chem. Phys., 11, 8231-8256, doi:10.5194/acp-11-8231-2011, 2011.

Gaie-Levrel, F., Perrier, S., Perraudin, E., Stoll, C., Grand, N., and Schwell, M.: Development and characterization of a single particle laser ablation mass spectrometer (SPLAM) for organic aerosol studies, Atmos. Meas. Tech., 5, 225-241, doi:10.5194/amt-5-225-2012, 2012.

Gard, E., Mayer, J. E., Morrical, B. D., Dienes, T., Fergenson, D. P., and Prather, K. A.: Real-Time Analysis of Individual Atmospheric Aerosol Particles: Design and Performance of a Portable ATOFMS, Anal. Chem., 69, 4083-4091, doi:10.1021/ac970540n, 1997.

Gemayel, R., Hellebust, S., Temime-Roussel, B., Hayeck, N., Van Elteren, J. T., Wortham, H., and Gligorovski, S.: The performance and the characterization of laser ablation aerosol particle time-of-flight mass spectrometry (LAAP-ToF-MS), Atmos. Meas. Tech., 9, 1947-1959, doi:10.5194/amt-9-1947-2016, 2016.

Giorio, C., Tapparo, A., Dall'Osto, M., Beddows, D. C., Esser-Gietl, J. K., Healy, R. M., and Harrison, R. M.: Local and regional components of aerosol in a heavily trafficked street canyon in central London derived from PMF and cluster analysis of single-particle ATOFMS spectra, Environ. Sci. Technol., 49, 3330-3340, 2015.

Gross, D. S., Gälli, M. E., Silva, P. J., and Prather, K. A.: Relative sensitivity factors for alkali metal and ammonium cations in single-particle aerosol time-of-flight mass spectra, Anal. Chem., 72, 416-422, 2000.

Healy, R. M., Sciare, J., Poulain, L., Kamili, K., Merkel, M., Müller, T., Wiedensohler, A., Eckhardt, S., Stohl, A., Sarda-Estève, R., McGillicuddy, E., O’Connor, I. P., Sodeau, J. R., and Wenger, J. C.: Sources and mixing state of size-resolved elemental carbon particles in a European megacity: Paris, Atmos. Chem. Phys., 12, 1681-1700, doi:10.5194/acp-12-1681-2012, 2012.

Heim, M., Mullins, B. J., Umhauer, H., and Kasper, G.: Performance evaluation of three optical particle counters with an efficient "multimodal" calibration method, J. Aerosol Sci., 39, 1019-1031, doi:10.1016/j.jaerosci.2008.07.006, 2008.

Hinz, K.-P. and Kaufmann, R.: Simultaneous Detection of Positive and Negative Ions From Single Airborne Particles by Real- 
time Laser Mass Spectrometry, Aerosol Sci. Tech., 24, 233-242, 1996.

Hinz, K.-P. and Spengler, B.: Instrumentation , data evaluation and quantification in on-line aerosol mass spectrometry, J. Mass Spectrom., 42, 843-860, doi:10.1002/jms.1262, 2007.

Hinz, K.-P., Erdmann, N., Grüning, C., and Spengler, B.: Comparative parallel characterization of particle populations with two mass spectrometric systems LAMPAS 2 and SPASS, Int. J. Mass Spectrom., 258, 151-166, doi:10.1016/j.ijms.2006.09.008, 2006.

Hudson, J. G., Noble, S., and Jha, V.: On the relative role of sea salt cloud condensation nuclei (CCN), J. Atmos. Chem., 68, 71-88, doi:10.1007/s10874-011-9210-5, 2011.

Huffman, J. A., Jayne, J. T., Drewnick, F., Aiken, A. C., Onasch, T., Worsnop, D. R., and Jimenez, J. L.: Design, Modeling, Optimization, and Experimental Tests of a Particle Beam Width Probe for the Aerodyne Aerosol Mass Spectrometer, Aerosol Sci. Tech., 39, 1143-1163, doi:10.1080/02786820500423782, 2005.

Jayne, J. T., Leard, D. C., Zhang, X., Davidovits, P., Smith, K. A., Kolb, C. E., and Worsnop, D. R.: Development of an Aerosol Mass Spectrometer for Size and Composition Analysis of Submicron Particles, Aerosol Sci. Tech., 33, 49-70, doi:10.1080/027868200410840, 2000.

Jonsson, H. H., Wilson, H. C., and Brock, R. G.: Performance of a focused cavity aerosol spectrometer for measurements in the stratosphere of particle size in the 0.06-2.0 $\mu \mathrm{m}$ diamater range, American Meteorological Society, 12, 115-129, 1995.

Kandler, K., Lieke, K., Benker, N., Emmel, C., Küpper, M., MÜllerEbert, D., Ebert, M., Scheuvens, D., Schladitz, A., Schütz, L., and Weinbruch, S.: Ground-based off-line aerosol measurements at Praia, Cape Verde, during the Saharan Mineral Dust Experiment: Microphysical properties and mineralogy, Chemical and Physical Meteorology, 63, 459-474, doi:10.1111/j.16000889.2011.00546.x, 2011.

Kane, D. B. and Johnston, M. V.: Size and composition biases on the detection of individual ultrafine particles by aerosol mass spectrometry, Environ. Sci. Technol., 34, 4887-4893, 2000.

Liu, P., Ziemann, P. J., Kittelson, D. B., and McMurry, P. H.: Generating particle beams of controlled dimensions and divergence: II. Experimental evaluation of particle motion in aerodynamic lenses and nozzle expansions, Aerosol Sci. Tech., 22, 314-324, 1995.

McMurry, P. H.: A review of atmospheric aerosol measurements, Atmos. Environ., 34, 1959-1999, 2000.

Middlebrook, A. M., Murphy, D. M., Lee, S.-H., Thomson, D. S., Prather, K. A., Wenzel, R. J., Liu, D.-Y., Phares, D. J., Rhoads, K. P., Wexler, A. S., et al.: A comparison of particle mass spectrometers during the 1999 Atlanta Supersite Project, J. Geophys. Res.-Atmos., 108, 8424, doi:10.1029/2001JD000660, 2003.

Moffet, R. C. and Prather, K. A.: In-situ measurements of the mixing state and optical properties of soot with implications for radiative forcing estimates, P. Natl. Acad. Sci. USA, 106, 1187211877, doi:10.1073/pnas.0900040106, 2009.

Murphy, D. M.: The Design of Single Particle Mass Spectrometers, Mass Spectrom. Rev., 26, 150-165, doi:10.1002/mas.20113, 2007.

Murphy, D. M. and Thomson, D. S.: Laser Ionization Mass Spectroscopy of Single Aerosol Particles, Aerosol Sci. Tech., 22, 237249, doi:10.1080/02786829408959743, 1995.
Murphy, D., Cziczo, D., Hudson, P., Schein, M., and Thomson, D.: Particle density inferred from simultaneous optical and aerodynamic diameters sorted by composition, J. Aerosol Sci., 35, 135139, doi:10.1016/S0021-8502(03)00386-0, 2004.

Nash, D. G., Baer, T., and Johnston, M. V.: Aerosol mass spectrometry: An introductory review, Int. J. Mass Spectrom., 258, 2-12, doi:10.1016/j.ijms.2006.09.017, 2006.

Peña, O. and Pal, U.: Scattering of electromagnetic radiation by a multilayered sphere, Comput. Phys. Commun., 180, 2348-2354, doi:10.1016/j.cpc.2009.07.010, 2009.

Petrucci, G., Farnsworth, P., Cavalli, P., and Omenetto, N.: A differentially pumped particle inlet for sampling of atmospheric aerosols into a time-of-flight mass spectrometer: Optical characterization of the particle beam, Aerosol Sci. Tech., 33, 105-121, doi:10.1080/027868200410877, 2000.

Pope, C. A. and Dockery, D. W.: Health Effects of Fine Particulate Air Pollution : Lines that Connect, J. Air Waste Manage., 56, 709-742, 2006.

Prather, K. A., Nordmeyer, T., and Salt, K.: Real-time Characterization of Individual Aerosol Particles Using Time-ofFlight Mass Spectrometry, Anal. Chem., 66, 1403-1407, doi:10.1021/ac00081a007, 1994.

Pratt, K. A. and Prather, K. A.: Aircraft measurements of vertical profiles of aerosol mixing states, J. Geophys. Res., 115, D11305, doi:10.1029/2009JD013150, 2010.

Pratt, K. A., Mayer, J. E., Holecek, J. C., Moffet, R. C., Sanchez, R. O., Rebotier, T. P., Furutani, H., Gonin, M., Fuhrer, K., Su, Y., Guazzotti, S., and Prather, K. A.: Development and characterization of an aircraft aerosol time-of-flight mass spectrometer, Anal. Chem., 81, 1792-1800, doi:10.1021/ac801942r, 2009.

Reilly, P. T. A., Lazar, A. C., Gieray, R. A., Whitten, W. B., and Ramsey, J. M.: The Elucidation of Charge-Transfer-Induced Matrix Effects in Environmental Aerosols Via Real-Time Aerosol Mass Spectral Analysis of Individual Airborne Particles, Aerosol Sci. Tech., 33, 135-152, doi:10.1080/027868200410895, 2000.

Reinard, M. S. and Johnston, M. V.: Ion formation mechanism in laser desorption ionization of individual nanoparticles, J. Am. Soc. Mass Spectr., 19, 389-399, doi:10.1016/j.jasms.2007.11.017, 2008.

Reitz, P., Spindler, C., Mentel, T. F., Poulain, L., Wex, H., Mildenberger, K., Niedermeier, D., Hartmann, S., Clauss, T., Stratmann, F., Sullivan, R. C., DeMott, P. J., Petters, M. D., Sierau, B., and Schneider, J.: Surface modification of mineral dust particles by sulphuric acid processing: implications for ice nucleation abilities, Atmos. Chem. Phys., 11, 7839-7858, doi:10.5194/acp-117839-2011, 2011.

Sierau, B., Chang, R. Y.-W., Leck, C., Paatero, J., and Lohmann, U.: Single-particle characterization of the high-Arctic summertime aerosol, Atmos. Chem. Phys., 14, 7409-7430, doi:10.5194/acp14-7409-2014, 2014.

Su, Y., Sipin, M. F., Furutani, H., and Prather, K. A.: Development and Characterization of an Aerosol Time-of-Flight Mass Spectrometer with Increased Detection Efficiency, Anal. Chem., 76, 712-719, doi:10.1021/ac034797z, 2004.

Sullivan, R. C. and Prather, K. A.: Recent advances in our understanding of atmospheric chemistry and climate made possible by on-line aerosol analysis instrumentation, Anal. Chem., 77, 386185, doi:10.1021/ac050716i, 2005. 
Sullivan, R. C., Guazzotti, S. A., Sodeman, D. A., and Prather, K. A.: Direct observations of the atmospheric processing of Asian mineral dust, Atmos. Chem. Phys., 7, 1213-1236, doi:10.5194/acp-7-1213-2007, 2007.

Tang, I. N., Tridico, A. C., and Fung, K. H.: Thermodynamic and optical properties of sea salt aerosols, J. Geophys. Res.-Atmos., 102, 23269-23275, 1997.

Thomson, D. S., Schein, M. E., and Murphy, D. M.: Particle analysis by laser mass spectrometry WB-57F instrument overview, Aerosol Sci. Tech., 33, 153-169, doi:10.1080/027868200410903, 2000.

Trimborn, A., Hinz, K. P., and Spengler, B.: Online Analysis of Atmospheric Particles with a Transportable Laser Mass Spectrometer, Aerosol Sci. Tech., 33, 191-201, doi:10.1080/027868200410921, 2000.

Vaden, T. D., Imre, D., Beránek, J., and Zelenyuk, A.: Extending the Capabilities of Single Particle Mass Spectrometry: II. Measurements of Aerosol Particle Density without DMA, Aerosol Sci. Tech., 45, 125-135, doi:10.1080/02786826.2010.526156, 2011.

Williams, L. R., Gonzalez, L. A., Peck, J., Trimborn, D., McInnis, J., Farrar, M. R., Moore, K. D., Jayne, J. T., Robinson, W. A., Lewis, D. K., Onasch, T. B., Canagaratna, M. R., Trimborn, A., Timko, M. T., Magoon, G., Deng, R., Tang, D., de la Rosa Blanco, E., Prévôt, A. S. H., Smith, K. A., and Worsnop, D. R.: Characterization of an aerodynamic lens for transmitting particles greater than 1 micrometer in diameter into the Aerodyne aerosol mass spectrometer, Atmos. Meas. Tech., 6, 3271-3280, doi:10.5194/amt-6-3271-2013, 2013.
Zelenyuk, A. and Imre, D.: Single Particle Laser Ablation Time-ofFlight Mass Spectrometer: An Introduction to SPLAT, Aerosol Sci. Tech., 39, 554-568, doi:10.1080/027868291009242, 2005.

Zelenyuk, A., Yang, J., Choi, E., and Imre, D.: SPLAT II: An Aircraft Compatible, Ultra-Sensitive, High Precision Instrument for In-Situ Characterization of the Size and Composition of Fine and Ultrafine Particles, Aerosol Sci. Tech., 43, 411-424, doi:10.1080/02786820802709243, 2009.

Zelenyuk, A., Ezell, M. J., Perraud, V., Johnson, S. N., Bruns, E. A., Yu, Y., Imre, D., Alexander, M. L., and Finlayson-Pitts, B. J.: Characterization of organic coatings on hygroscopic salt particles and their atmospheric impacts, Atmos. Environ., 44, 1209-1218, doi:10.1016/j.atmosenv.2009.11.047, 2010.

Zhang, X., Smith, K. A., Worsnop, D. R., Jimenez, J. L., Jayne, J. T., Kolb, C. E., Morris, J., and Davidovits, P.: Numerical Characterization of Particle Beam Collimation: Part II Integrated Aerodynamic-Lens-Nozzle System, Aerosol Sci. Tech., 38, 619638, doi:10.1080/02786820490479833, 2004.

Zhou, L., Rai, A., and Zachariah, M. R.: Component and morphology biases on quantifying the composition of nanoparticles using single-particle mass spectrometry, Int. J. Mass Spectrom., 258, 104-112, doi:10.1016/j.ijms.2006.07.006, 2006. 